\title{
6ylunthed
}

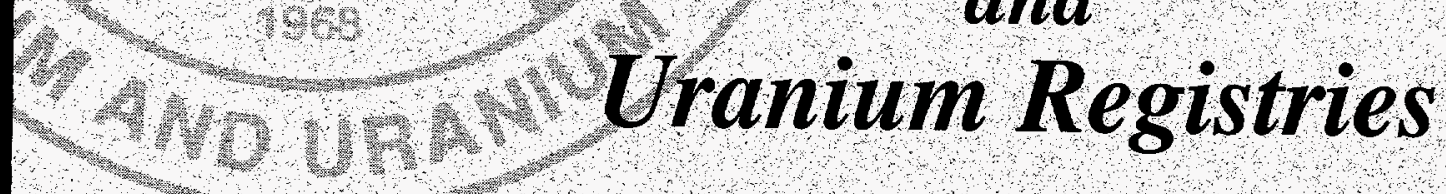

\section{United States Transuranium}

\section{and}

ANNUAL REPORT FEBRUARY 1, 2000 - JANUARY 31, 2001

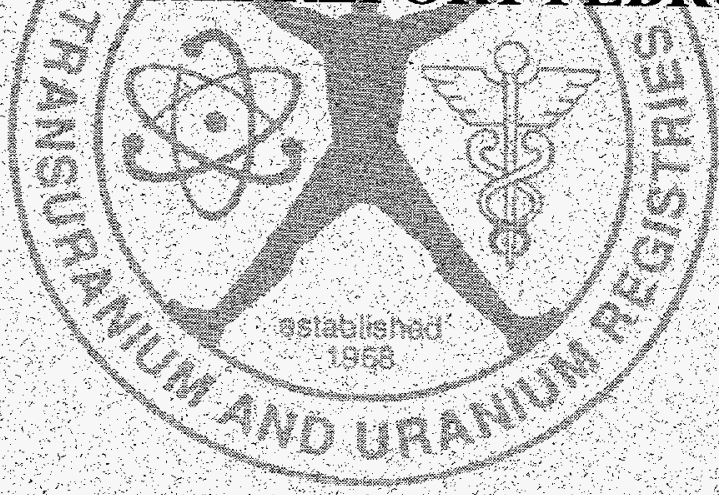

WASHINGTON STATE UUNIVERSTTY 


\section{DISCLAIMER}

This report was prepared as an account of work sponsored by an agency of the United States Government. Neither the United States Government nor any agency thereof, nor any of their employees, make any warranty, express or implied, or assumes any legal liability or responsibility for the accuracy, completeness, or usefulness of any information, apparatus, product, or process disclosed, or represents that its use would not infringe privately owned rights. Reference herein to any specific commercial product, process, or service by trade name, trademark, manufacturer, or otherwise does not necessarily constitute or imply its endorsement, recommendation, or favoring by the United States Government or any agency thereof. The views and opinions of authors expressed herein do not necessarily state or reflect those of the United States Government or any agency thereof. 


\section{DISCLAIMER}

Portions of this document may be illegible in electronic image products. Images are produced from the best available original document. 


\title{
UNITED STATES TRANSURANIUM AND URANIUM REGISTRIES
}

\section{RESEARCHING RADIATION PROTECTION}

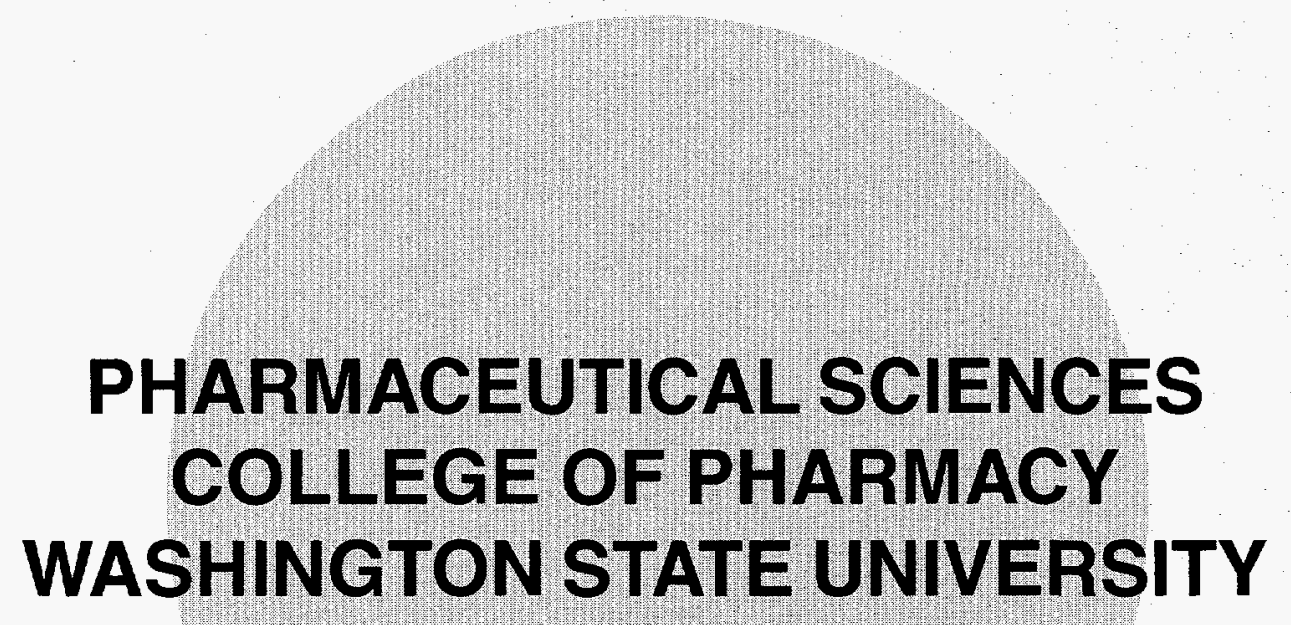

COMPILED AND EDITED

SUSAN M. EHRHART and RONALD E. FILIPY

CONTRIBUTORS

J.R. ALLDREDGE, T.L. BRUMBAUGH, G.B. DECKERT, S.M. EHRHART, J.T. ELLISTON, R.E. FILIPY, M.V. PHAM, J.J. RUSSELL, D.B. STUIT, R.G.THOMAS

\author{
2710 UNIVERSITY DRIVE \\ RICHLAND, WA 99352 \\ TOLL-FREE: (800)375-9317 \\ PHONE: (509)372-7317 \\ FAX: (509)375-1817 \\ FAX: (509)372-7160
}




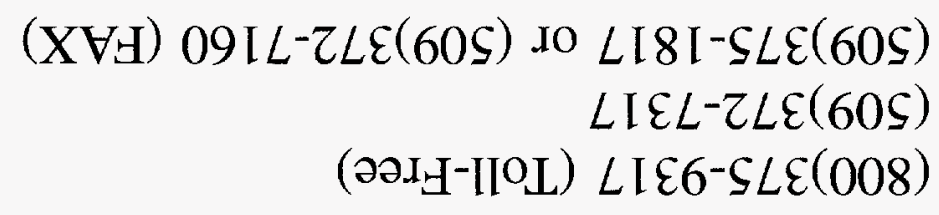

乙SE66 VM 'pue[บว!्

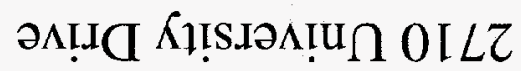

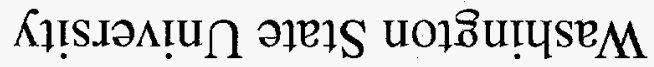

zuoyd

SSsppt

nрә'nsM:Inqsn'MMM

gaM $\partial p: M P J 10 M$

\section{"' Sn HOVEY OLMOH}

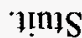

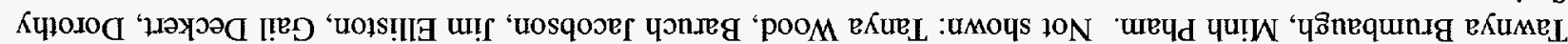

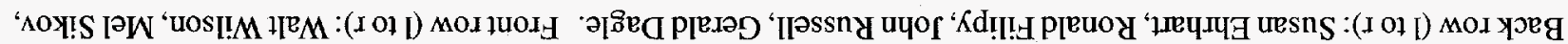

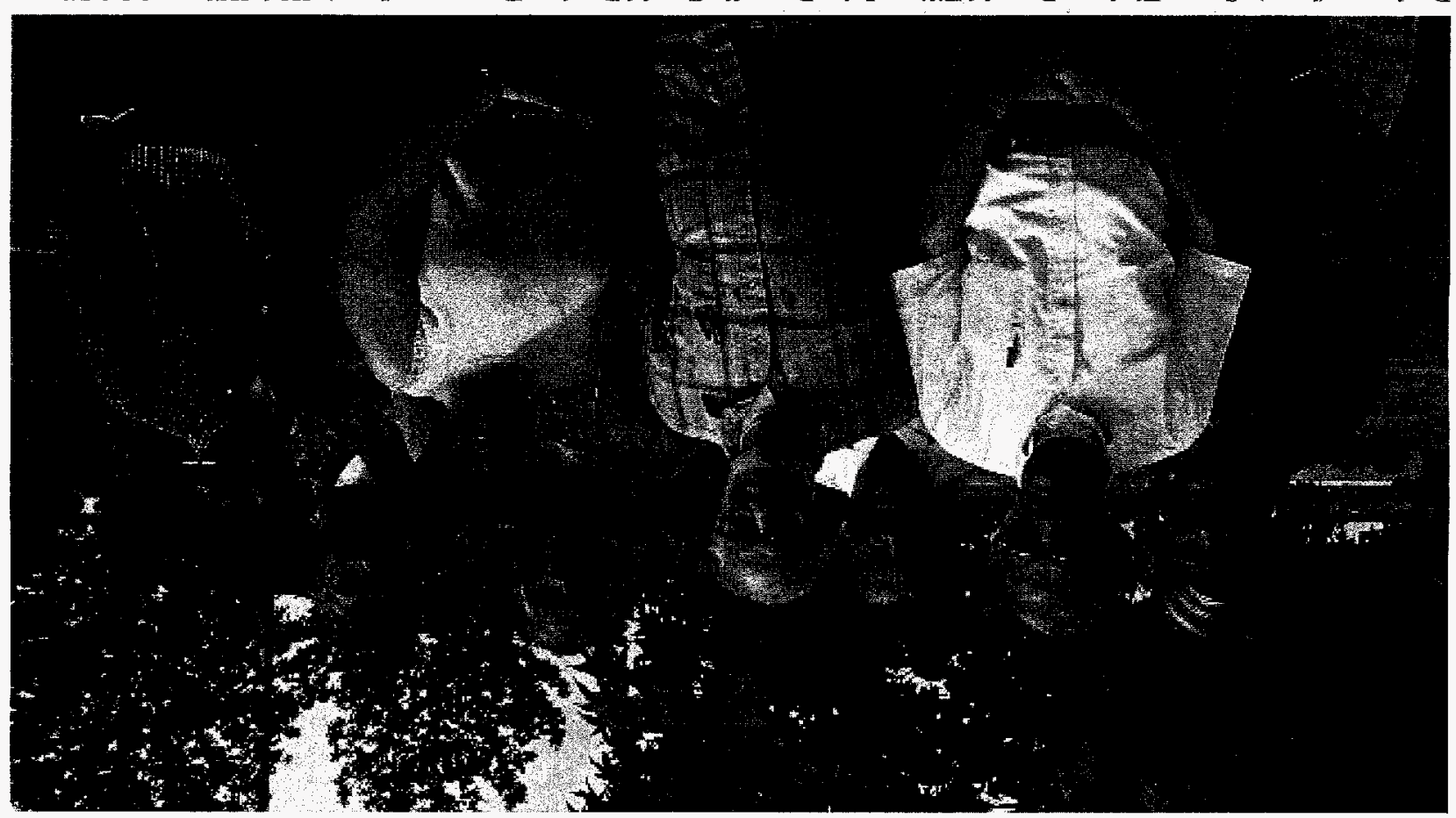


TABLE OF CONTENTS 4

DIRECTOR'S MESSAGE 5 BY RONALD E. FILIPY, DIRECTOR

FACULTY and STAFF 6

HIGHLIGHTS OF 2000 7 BY RONALD E. FILIPY, DIRECTOR

FUNDING SOURCES 9 By Susan M. Ehrhart, ProgRam AdminISTRATIVE ManaGiek

REGISTRANT CATEGORIZATION and STATISTICS 10

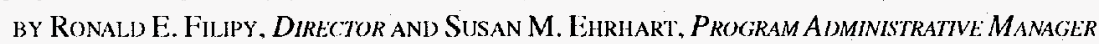

ANALYSES OF WHOLE BODY DONATIONS BY RONALD E. FILIPY, DIRECTOR

COLLABORATIVE RESEARCH PROJECTS 19 BY USTUR FACULTY AND STAFF

COMMITTEE APPOINTMENTS 21 hy USTUR Faculty

INFORMATION SYSTEMS

hy Minh V. Pham, Sustems Analyst and Tawnya Brumbaugh, Secretary

RADIOCHEMISTRY OPERATIONS

hy James T. Ellistion. Director of Radiochemistry

NATIONAL HUMAN RADIOBIOLOGY TISSUE REPOSITORY

by John J. Russell, Associate Director

NATIONAL RADIOBIOLOGY ARCHIVES

hy John J. Russell, Associate Director

DATA MANAGEMENT

hy Ronald E. lilipy. Director and J. Richard Alldredge, Statistician

THE EFFECT OF CHELATION THERAPY ON URINARY EXCRETION OF

PLUTONIUM IN A USTUR WHOLE BODY DONOR

by Ronald E. IFilipy. Director

PUBLICATIONS AND PRESENTATIONS

by Susan M. lihrhart. Program Administrative Manager

ADVISORY COMMITTEE HIGHLIGHTS

hy Rohert (i. Thomas. Advisony Committe Chai

APPENDIX A - ABSTRACTS .50

hy Susan M. Ihrhart, Program Administrative Manager 


\title{
DIRECTOR's MESSAGE
}

\begin{abstract}
Cast year, I indicated that we, at the USTUR, were heavily involved in making the USTUR database useful for collaborative research projects. Since, then we have engaged in a few collaborative projects that have already borne fruit. But, the time has come for those scientists out there who would like to use some data based on human experience with actinide elements. There are three obvious ways that USTUR data and materials could be the basis for a collaborative research project:
\end{abstract}

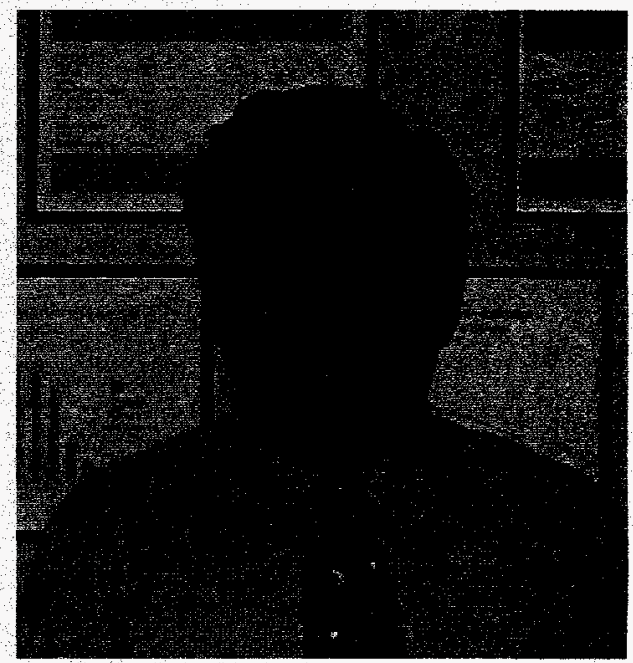

1. The measured actinide contents of tissues donated to the USTUR could be compared with estimates of those contents that were made while the donor was alive and working at one of the many worksites of our Registrants. This kind of project would involve radiation protection and/or medical personnel at the specific work sites of USTUR donors.

2. The data of the USTUR include the results of bioassays as well as records of exposure incidents in addition to the measured contents of body organs of occupationally exposed individuals. These data can be used to describe the depositions and biokinetics of actinide elements in the human body for the verification of dosimetry models dealing with those elements or construction of new models as needed.

3. The National Human Radiobiological Tissue Repository (NHRTR) contains donated tissue samples preserved in a frozen state $\left(-70^{\circ} \mathrm{C}\right)$ that could be used for molecular cytogenetic studies of the microscopic and submicroscopic effects of internal alpha radiation. Furthermore, the precise actinide contents of those tissue samples were measured by the USTUR so that estimates of radiation doses to the organs can be easily calculated. These samples are from the same donors whose radiation exposure records and bioassay results are included in the USTUR database.

These three examples represent the most obvious bases for collaborative research projects. The USTUR staff members are not experts in all those areas and have limited time for writing proposals, performing experiments, and reporting results; however, we do have the data and biological materials. The USTUR and its sponsors invite inquiries from all interested scientists. Telephone numbers, e-mail addresses, and mailing addresses are included throughout this report.

Let's hear from you!

Ronald E. Filipy, Director 


\section{FACULTY, STAFF, AND COMMITTEE}

\section{Faculty}

Ronald E. Filipy, Director

John J. Russell, James T. Elliston, Dorothy B. Stuit, Gail B. Deckert, J. Richard Alldredge,

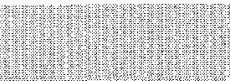
Associate Director Director of Radiochemistry Radiochemist ..Radiochemist Statistician

\section{Adjunct Faculty}

Melvin R. Sikov, Adjunct Professor Gerald E. Dagle, Associate Professor Baruch Gold, Associate Professor Mike R. Cummings, Adjunct Assistant Professor Baruch S. Jacobson, Adjunct Scientist

\section{Administrative Professionals}

Susan M. Ehrhart, .....Program Administrative Manager Minh V. Pham, Systems Analyst Tanya G. Wood, Scientific Assistant

\section{Classified Staff}

Tawnya L. Brumbaugh, Secretary Cathy Grimm, .Research Technologist

\section{STUDENTS}

Rosa Padilla, Undergraduate Workstudy Student

Rosara Payne, Undergraduate Workstudy Student

\section{Advisory Committee}

Robert G. Thomas, Committee Chair Ronald Brosemer. .Committee Member Joe Aldrich, Committee Member

Kathryn Paxton George, Committee Member Mark Griffon, Committee Member

Isabel Fisenne, Committee Member

Dennis Mahlum. Committee Member 


\section{HIGHLIGHTS OF 2000}

The year, 2000, was a very good year! One of the brightest "highlights" involves the progress made toward making the USTUR database accurate and useful to scientists other than USTUR staff members. The vast majority of medical and exposure history information regarding USTUR registrants has been collected. A large portion of that information (all information for deceased registrants) has been entered into the USTUR database with verification of the entries. The USTUR radiochemistry laboratories have processed a large number of tissue samples and the results have been entered into the database. Verification of entries in the radiochemistry database table is currently underway and the tissue identifiers have been standardized to facilitate specific queries.

\section{Inquiries}

A large amount of USTUR staff time, during the past year, was occupied with responses to inquiries from USTUR registrants and their families, other former workers of Department of Energy (DOE) sites, and other governmental agencies such as the Department of Defense (DOD). Generally, inquiries from the former workers were a result of the DOE program announcing the possibility of some monetary compensation for work-related illnesses; a number of them have the mistaken impression that the USTUR is associated with that program. They are assured that an autopsy by the USTUR will not necessarily make them eligible for compensation under the program and they are given the telephone "hotline" number for further information. The DOD-related in- quiries generally deal with the issue of exposure to depleted uranium used in armor-piercing munitions. John Russell, USTUR, has served as a member of the presidential oversight committee whose charge is to investigate the possibility of harmful health effects of depleted uranium.

Largely because of this interest in the USTUR by non-scientists, the USTUR staff has prepared a description of the program, written in laymen's terms. This paper addresses the mission of the USTUR with a brief summary of the program's accomplishments in the areas of actinide element biokinetics, dosimetry, and the limited assessment of health effects of the actinide elements. Excerpts from the paper were included in an annual newsletter to USTUR Registrants and it is used in response to inquiries by the news media. It has also been used by the DOE program manager as a tool for briefing government officials who may be unfamiliar with the program and are not necessarily fluent in scientific terminology. Information from the paper was used in a recent revision of a brochure that is distributed to potential registrants and, at scientific meetings, to scientists who might be interested in working with USTUR data and materials. The USTUR "White Paper" can be found on the USTUR web site at www.ustur.wsu.edu.

\section{Advisory Committee Meeting}

The USTUR Advisory Committee met with WSU and USTUR faculty and staff members in the autumn of 2000. Once again, this was a very profitable two days for the USTUR. Al- 
though discussion was spirited and many solutions to problems were proposed, some of the problems discussed remained unresolved. Fortunately, the Advisory Committee consented to a series of conference telephone calls at periodic intervals during the year and the additional time and thought has led to solutions of the unresolved issues. Through the years, the advice of this committee has proved invaluable to the operation of the USTUR. The report of the USTUR Advisory Committee is included in this report.

\section{Research Results}

Five major manuscripts describing some of the USTUR activities have been prepared for publication in the scientific literature. In addition, results of USTUR research were presented at scientific meetings and published as abstracts or as proceedings of those meetings. These activities represent important vehicles for passing the word about the USTUR and its unique information regarding the human experience with intakes, retention, and dosimetry of the actinide elements.

\section{Advisory Committee}

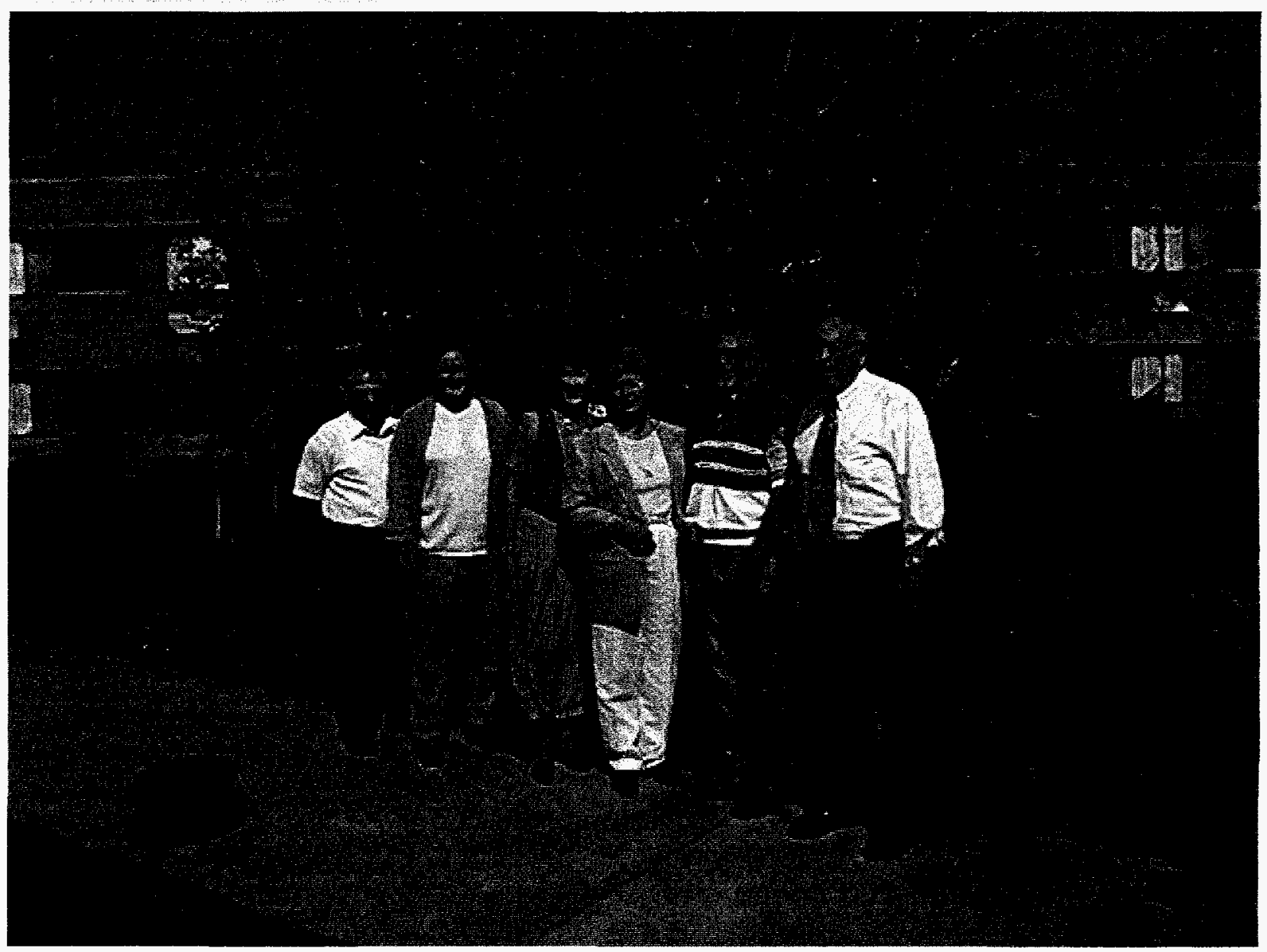

(1 to r) Joe Aldrich, Isabel Fisenne, Barbara Brooks, Kathryn Paxton-George, Ron Brosemer, Bob Thomas 
FUNDING SOURCES

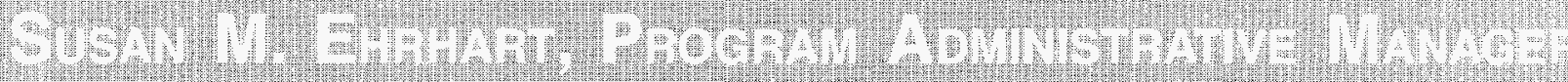

Total FY00 research program funding sources:

Federal -

Grant

U.S. Department of Energy

Office of Health Studies

Management and operation of the United

States Transuranium and Uranium Reg-

istries

DE-FG06-92EH89181

$\$ 1,000,000(02 / 1 / 00-01 / 31 / 01)$

Grant

U.S. Department of Energy

Office of Biological and Environmental

Research

Operation of the National Radiobiology

Archives

DE-FC03-96ER62213

$\$ 50,000(01 / 01 / 00-12 / 31 / 00)$

Non Federal -

Subcontract

University of Colorado

Health Sciences Center

Uncertainty Analyses to Characterize Plu-

tonium Exposure

R01/CCR815762

$\$ 25,001(08 / 01 / 00-07 / 31 / 01)$
The level of sponsored program activity for grants and subcontracts at USTUR was $\$ 1,075,001$ for FY00. The USTUR has had a $14 \%$ decrease in program activity from grants and subcontracts compared to the level of funding in FY98. Historically, the level of funding for the two previous fiscal years were as follows:

FY98 \$1,256,978.00

FY99 \$1,121,528.00

This has greatly reduced the FTE level within the USTUR from 13.05 FTE in FY98, 14.37 FTE in FY99 to the present 10.09 FTE for FY00.

\section{Proposals Submitted}

The USTUR submitted 2 federal proposals during FY00 and one federal flow-through subcontract. One proposal and subcontract were funded at $100 \%$ of the requested funding level. The main proposal to operate the USTUR was funded at the same level as it has been for the past three years. 


\section{REGISTRANT CATEGORIZATION AND STATISTICS}

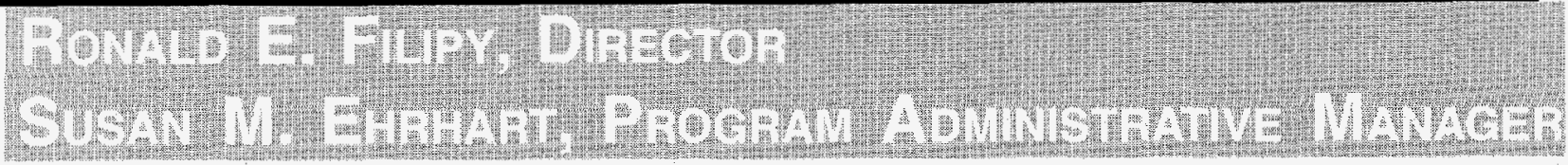

\section{Registrant Categorization}

When the U.S. Transuranium Registry and the U. S. Uranium Registry were formed, virtually anyone who was willing to commit to a tissue donation was enrolled as a participant whether or not they had significant body burdens of the actinide elements. This practice was intended to assure that radiochemical analytical results would be available from donors covering a wide range of actinide content, including those donors whose actinide intake was solely from environmental sources. Approximately 15-20 years ago, a number of participants with no occupational exposures to the actinides were dropped from the rolls of the programs because the actinide contents of their tissues were expected to be below the levels of detection of the radioanalytical methods in use at the time.

Once again, the USTUR is forced to prioritize resources, this time for two reasons: (1) because of the high costs associated with performance of autopsies and radiochemical analyses, and, (2) because of the generosity of such a large number of workers and former workers who have provided the USTUR with large amounts of certain kinds of information about the deposition, translocation, retention, and dosimetry of the actinide elements in the human body. For those reasons. the USTUR staff has conducted an extensive review of the dosimetry files of living USTUR participants and grouped them into three categories:
Category 1 - Significant actinide exposure with past or present positive bioassay results. These participants were considered very important to the USTUR for a variety of reasons such as a unique route of actinide intake (through the skin via wounds) or the deposition of an unusual radionuclide or chemical form of a nuclide;

Category 2 - Relatively high external radiation dose or professed exposures to beryllium, asbestos, or chemical solvents, but with minimal body burdens of the actinide elements. These participants, though not vitally important to the original mission of the USTUR, are likely to be important as a future resource as those ancillary exposures become more widely studied; and,

Category 3 - Not likely to have had any intakes of actinide intakes based on bioassay results and work histories and the tissues donated by these individuals would likely have actinide contents that are barely measurable. The autopsy agreements of these participants will not be renewed by the USTUR.

For the past three years, the USTUR has employed an expedited radioanalytical protocol with tissues from autopsies; that protocol and its use are explained in the Radiochemistry Operations section of this report. Briefly, four or five of the major organs are analyzed to estimate an actinide body burden and, if the estimate is very low, the remainder of the organs 
are given a low priority for completion of the analyses. It was anticipated that tissues from donors of Category 3 would fall into the low priority designation; therefore, the costs of autopsies and radiochemical analyses are expected to be reduced substantially with the implementation of this plan. Though economically necessary, this was not an easy decision for the USTUR staff in that a large number of registrants in Category 3 have been with the USTUR for many years and have renewed their agreements to donate tissues a number of times. Their loyalty to the program is much appreciated.

\section{Registrant Statistics}

As of January 31, 2001, the Registries had a total of 910 Registrants in all categories. Of that number, 202 were living Registrants and 341 Registrants were deceased. There were
366 Registrants in an "inactive" category which includes those with whom we have lost contact, those whose agreements have lapsed, and those who passed away without notification to the Registries.

\section{Medical/Dosimetry Records}

The USTUR has requested and received medical records for all but 12 living Registrants. Of the 12 , five are uranium miner workers whose records are not obtainable. The Registries have acquired all but 14 medical records for the deceased Registrants as well, and 12 of the 14 are uranium miners, whose records cannot be obtained.

\section{Figure 1}

Categorization of living Registrants

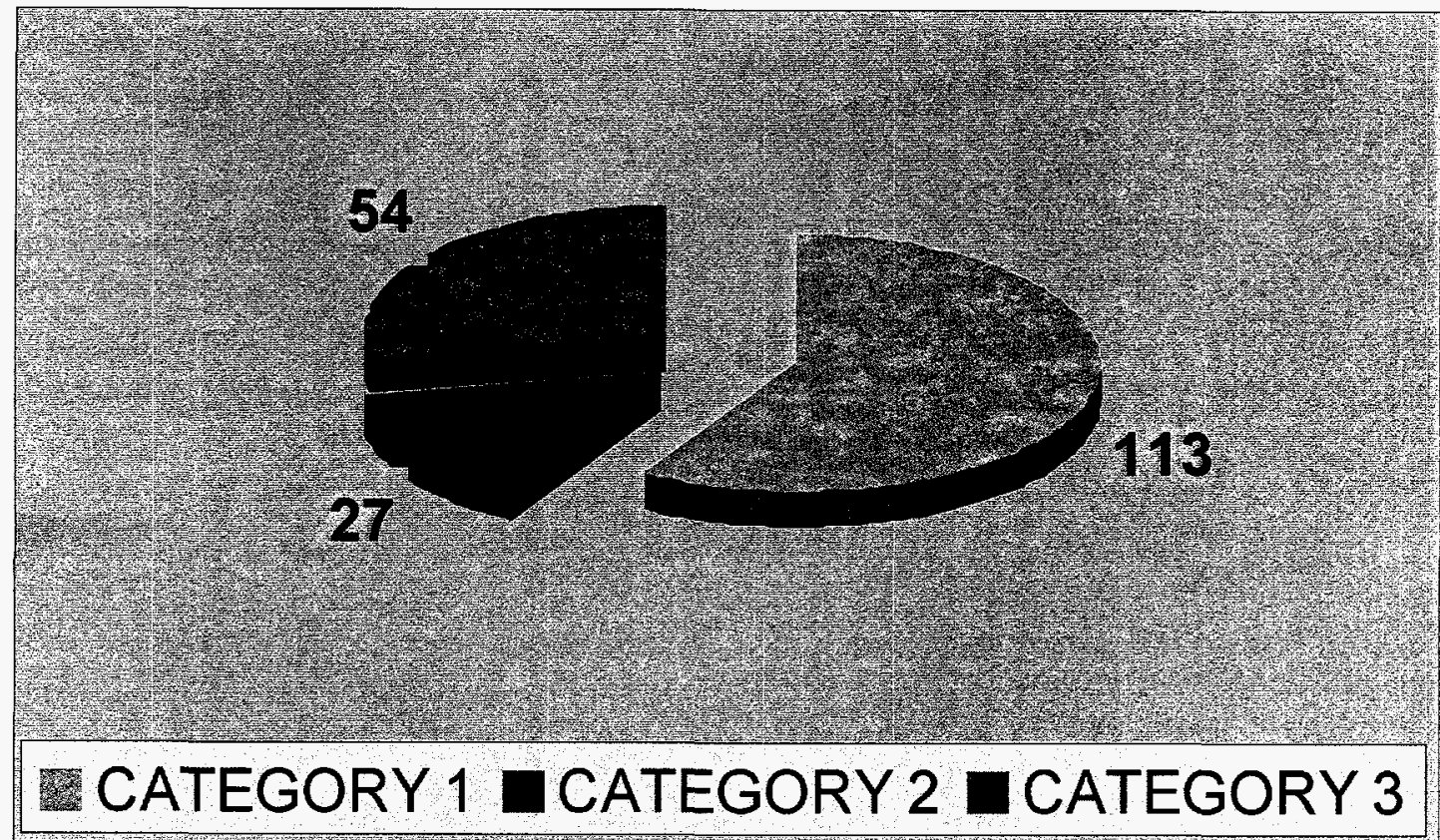


Figure 2 shows the types of tissue donations for living and deceased registrants. There were 25 deceased whole body donors, 311 deceased routine donors (routine autopsy) and 5 deceased donors classified as special donors. There are 18 living whole body donors, 178 living routine donors and 6 living donors classified as special. Figure 3 shows the Registrant status (living, deceased, or inactive) by worksite.

Figure 2

Types of tissue donations by USTUR living and deceased Registrants

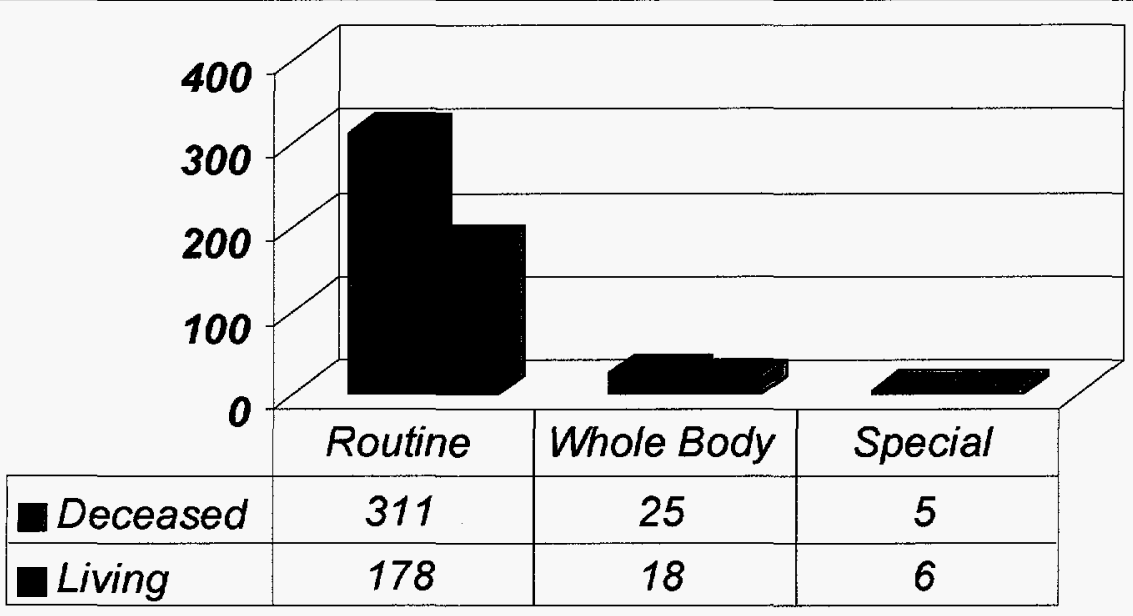

Figure 3

Status of tissue donors by worksite

BRI - British

FER - Fernald

HAN - Hanford

LOS - Los Alamos

MND - Mound

OAK - Oak Ridge

ROC - Rocky Flats

SVR - Savannah River

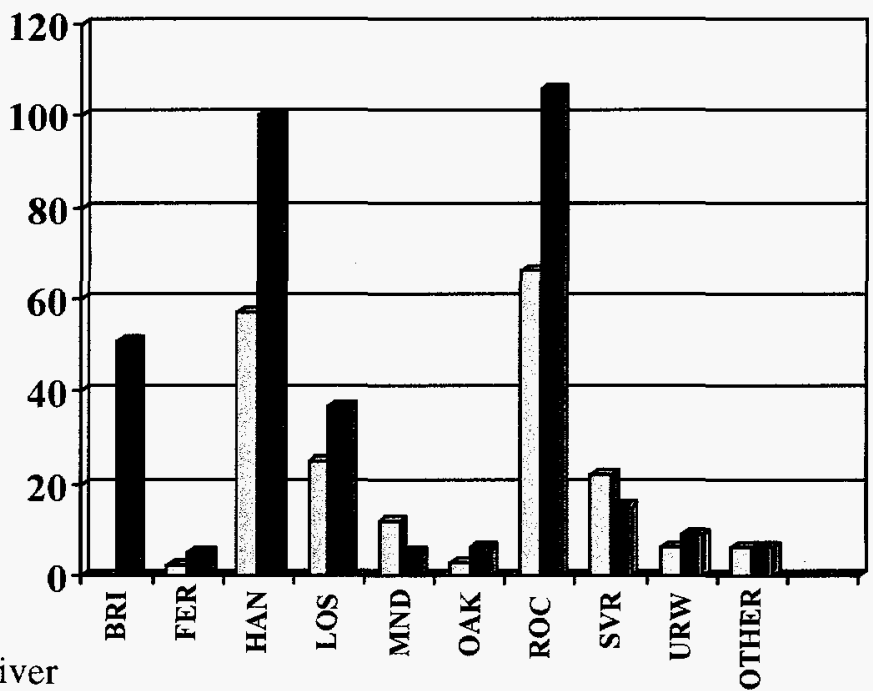

LIVING

DECEASED

URW - Uranium Mine Workers 


\section{ANALYSES OF WHOLE BODY DONATIONS}

\section{Progress}

There has been very good progress in the analyses of tissue samples from whole body donations to the USTUR during the past two years. Part of that progress is a result of the increased diligence of the USTUR radiochemistry laboratories and part is because of a modification of the sampling procedures for whole bodies. The USTUR has begun combining samples into groups; for example, groups of small bones from the skeleton, such as the hands and wrist bones, are analyzed together rather than as individual samples. This overall reduction in the number of samples is possible because each individual bone from the first 8-9 whole body donations was analyzed individually and the results indicated that virtually no data would be lost as a result of combination of certain samples into groups.

This report contains the analytical results, in summary form, from six whole body donations for which analyses have recently been completed. Manuscripts describing some of the individual cases are in preparation for publication by USTUR staff members and the detailed analytical data are available to qualified researchers by request.

In the summary tables (Tables 1-6), actual tissue weights from the autopsies or dissections were used when available. For the earlier whole body donations, virtually all skin and skeletal muscle samples were analyzed and, in those cases, actual weights were used. For whole bodies analyzed more recently, only representative samples of those organs were ana- lyzed and the resulting actinide concentrations were used with organ weights from Reference Man (ICRP-23) to calculate organ contents. In all cases, one half of the bones of the skeleton were analyzed and the bone weights and actinide contents were extrapolated to those of the entire skeleton.

\section{USTUR Case 0262}

This Registrant was a plutonium worker for approximately 32 years. His primary intake of ${ }^{239+240+241} \mathrm{Pu}$ appeared to have been a result of a hand wound 33 years before his death, at age 72 , from metastatic hepatocellular carcinoma. The amount of plutonium deposition, based on urinary excretion, was estimated at $84 \mathrm{~Bq}$ of ${ }^{239+240} \mathrm{Pu}$ and $660 \mathrm{~Bq}$ of ${ }^{24 !} \mathrm{Pu}$. He had a lifetime whole body dose of $0.11 \mathrm{~Sv}$ from external sources. An exposure history, along with the actinide contents of individual tissue samples, were reported in the USTUR annual report for the period, October 1, 1995 - September 30, 1996 (USTUR-0072-97). Summarized data for the body contents of ${ }^{239+240} \mathrm{Pu}$ and ${ }^{241} \mathrm{Am}$ are shown in Table 1 ; the body contained less than $2.0 \mathrm{~Bq}$ of ${ }^{238} \mathrm{Pu}$ so those results were not shown.

\section{USTUR Case 0769}

This Registrant was a chemical operator involved with plutonium purification and recovery work and his primary actinide intake of ${ }^{2.31}+2411 \mathrm{Pu}$ probably involved inhalation exposures as well as intake via a hand wound within a two year period. The exposures occurred approximately 45 years before his death from 
an osteogenic osteosarcoma at age 66. Approximately $70 \mathrm{~Bq}$ was excised from the hand wound; however, no chelation therapy was administered. The body burden of Case 0769 was estimated to be approximately $580 \mathrm{~Bq}$ of plutonium shortly before his death. A more detailed exposure history as well as the actinide contents of individual analyzed tissues were reported in the USTUR annual report for the period, October 1, 1995 - September 30, 1996 (USTUR-0072-97) and the medical history was described by Voelz and Lawrence in Health Physics, vol. 61, 1991. Summarized ${ }^{239+240} \mathrm{Pu}$ contents of the major organ systems are shown in Table 2. Most organs had a ${ }^{241} \mathrm{Am}$ content of approximately $2 \%$ of the plutonium content and, therefore, the analyses for americium were not completed. Many of the samples had ${ }^{238} \mathrm{Pu}$ contents that were less than detectable levels so those results are also not shown in Table 2.

\section{USTUR Case 0269}

This Registrant was involved in an incident in which he was exposed, by inhalation, to plutonium nitrate, a relatively soluble form of plutonium. His plutonium intake was estimated to be $230 \mathrm{nCi}(8.51 \mathrm{kBq})$ of ${ }^{23}+24() \mathrm{Pu}$ and 1,840 $\mathrm{nCi}(68.1 \mathrm{kBq})$ of ${ }^{241} \mathrm{Pu}$. Chelation therapy with CaEDTA (Calcium ethylenediaminetetraacetic acid) was begun immediately and continued for approximately seven months; it was quite effective but was discontinued probably because of toxicity concerns. After a 2 year hiatus, chelation therapy was renewed with Ca DTPA (Calcium diethylenetriaminepentaacetic acid) and that was continued for approximately two years. An estimated $30 \mathrm{nCi}(1.1 \mathrm{kBq})$ was excreted as a result of the chelation therepy. Case 0269 died from extensive carcinomatosis secondary to prostatic carcinoma at 79 years of age, 38 years after the exposure incident. Summarized plutonium and americium organ contents are shown in Table 3. These data, with bioassay and chelation therapy data, have been compiled for a comprehensive case-study manuscript to be submitted for publication.

\section{USTUR Case 0744}

Registrant 0744 was a plutonium worker for 34 years and, during that time, he had a number of plutonium contaminated hand wounds. Two of the wounds in the early part of his work period required excision; bioassay data at those times indicated a substantial intake of plutonium approximately 32 years before his death. He was also involved in a number of potential inhalation exposure incidents although the bioassay data indicated smaller intakes. At termination of his employment, Case 0744 had an estimated systemic plutonium burden of $19 \mathrm{nCi}$ (700 Bq) with an estimated ${ }^{239+240} \mathrm{Pu}$ lung burden of $75-110 \mathrm{~Bq}$ of and $20 \mathrm{~Bq}$ of ${ }^{241} \mathrm{Am}$, based on in-vivo determinations. He also had a lifetime dose of $0.38 \mathrm{~Sv}$ from external radiation sources. Table 4 contains a summary of the organ contents of plutonium and americium at death. The data of Table 4 illustrates the accuracy of lung burden estimates made during life; however, the measured systemic burden of plutonium at death was only about $20 \%$ of the estimate made eight years prior to death.

\section{USTUR Case 1002}

This Registrant received the greater part of his exposure, by inhalation, during the first two years of his employment, 45-46 years before his death. He apparently worked with uranium for only the first 10 years of his career because bioassay and external dosimetry data were available for only that period of time. He sustained a lifetime dose of $0.043 \mathrm{~Sv}$ during that time. He died from a cerebellar infarct at the age of 83 years although the autopsy indicated a marked atherosclerotic condition. A summary of his organ uranium contents is shown in Table 5. Uranium was primarily measured in the tissues by Kinetic Phosphorescence Analysis 
(KPA) so values in Table 5 are presented as mass of uranium rather than as isotopic activity. A manuscript with a comprehensive analysis of this case has been prepared for submission for publication. This case represents the first completely analyzed whole body donation whose occupational exposure was primarily to uranium.

\section{USTUR Case 1028}

Registrant 1028 worked with uranium for 18 years when she was removed from that work because her bioassays indicated an abnormal pattern although there were no specific exposure incidents on file. She had an estimated lung burden of approximately $500 \mu \mathrm{g}$ at the time; however she continued working for another nine years until retirement. She died from a cerebral vascular accident at age 86,31 years after removal from work with uranium. A summary of her organ uranium contents is shown in Table 6; samples were measured by isotopic analysis and the values were converted to mass units for comparison with other uranium cases.

\section{Conclusion}

There were quite a variety of exposure histories and actinide deposition and retention characteristics among these six whole body donations to the USTUR and those, combined with the tissue analytical results, led to a number of interesting observations.

The data in Table 1 (Case 0262) appear to verify a wound as the route of entry of plutonium in that the left axillary lymph node contained approximately one-half of the total body burden at death and the lungs and pulmonary lymph nodes contained very little plutonium. This also indicates the involvement of a relatively insoluble form of plutonium because so much of it remained in the axillary lymph node for a residence time (RT) of 33 years. The in-vivo estimate of systemic plutonium deposition, based on urinalyses, was apparently quite accurate. By far, the greatest amount of systemic plutonium was sequestered in the axillary lymph node and not subject to urinary excretion.

It was evident, from the data in Tables 2-4, that Cases 0769 and 0744 had inhaled relatively insoluble forms of plutonium because the percents of the body burdens retained in the respiratory tracts were $8.1 \%$ and $38 \%$, respectively. Pulmonary lymph nodes of those two cases also contained substantial amounts of plutonium relative to those in the lungs. The lungs of Case 0269, who inhaled a relatively soluble form of plutonium only contained $1.2 \%$ of the body burden and the pulmonary lymph nodes contained relatively small amounts of plutonium.

The respiratory tracts of Cases 1002 and 1028 contained $80 \%$ and $62 \%$ of their body burdens of uranium, respectively, considerably more than observed for plutonium. These two donors had similar work experiences and the distribution of uranium in their bodies was also similar, with two notable differences. Case 1002 had a substantial fraction of his systemic uranium content in the spleen and that was not observed in Case 1028. Also, Case 1028 had a very high content of ${ }^{234} \mathrm{U}$ in her body. Isotopic measurement of selected tissues of Case 1002 indicated that his exposure was to natural uranium in that the contents of ${ }^{234} \mathrm{U}$ and ${ }^{238} \mathrm{U}$ were approximately equal. The isotopic ratios in tissues of Case 1028 indicate that her exposure was to an enriched form of uranium.

The data from the six whole body donations. summarize above. have added substantially to the knowledge of the retention and distribution of plutonium, americium, and uranium in the human body. Such data are extremely valuable for the interpretation of information from routine autopsy cases, donations of selected organ samples to the USTUR. For example, 
the method developed for extrapolation of actinide contents of individual bones to total skeletal content (described elsewhere in this report) was based solely on data from whole body donations. The USTUR has tissues from six additional whole body donations undergoing radiochemical analysis and the data from those donations will provide still more variety of exposure and medical histories to the USTUR database.

\section{Table 1}

Summary of plutonium and americium content in body organs of USTUR Case 0262 at death

\begin{tabular}{lccc}
\hline Tissue/Organ & Autopsy weight $(\mathrm{g})$ & ${ }^{234+240} \mathrm{Pu}(\mathrm{Bq})$ & ${ }^{241} \mathrm{Am}(\mathrm{Bq})$ \\
\hline Lungs & 1290.0 & 2.59 & 0.527 \\
Pulmonary lymph nodes & 18.1 & 1.05 & 0.20 \\
Liver & 2630.0 & 20.7 & 2.14 \\
Kidneys & 371.0 & 0.0527 & 0.0209 \\
Spleen & 204.0 & 3.06 & 0.555 \\
Smooth Muscle Organs & 1450.0 & 0.632 & 0.147 \\
Striated Muscle & 22900.0 & 1.20 & 0.509 \\
Other Muscle & 613.0 & 0.070 & 0.0190 \\
Skin & 46200.0 & 1.60 & 0.608 \\
Testes & 28.7 & 0.0177 & 0.00348 \\
Other soft tissue & 4040.0 & 1.38 & 0.384 \\
L. Axillary lymph node & $172)$ & 56.0 & 8.04 \\
R. Axillary lymph node ${ }^{(2)}$ & 28.7 & 0.0177 & 0.00348 \\
Skeleton & 9122.0 & 22.6 & 8.16 \\
\hline Systemic total & 87800.0 & 107.0 & 20.5 \\
Whole body total & 88900.0 & 111.0 & 21.2 \\
\hline
\end{tabular}

(1) Includes skin and subcutaneous adipose tissue.

(2) Includes adjacent connective and adipose tissue. 
TABIE 2

Summary of ${ }^{20+24 t}$ Pu content in body organs of USTUR Case 0769 at death

\begin{tabular}{lcc}
\hline Tissue/Organ & Autopsy weight $(\mathrm{g})$ & ${ }^{239+240} \mathrm{Pu}(\mathrm{Bq})$ \\
\hline Lungs & 1280.0 & 17.9 \\
Pulmonary lymph nodes & 10.6 & 4.24 \\
Liver & 1650.0 & 85.8 \\
Kidneys & 472.0 & 0.209 \\
Spleen & 135.0 & 1.32 \\
Smooth Muscle Organs & 1480.0 & 0.827 \\
Striated Muscle & 18200.0 & 6.80 \\
Other Muscle & 380.0 & 0.267 \\
Skin ${ }^{(1)}$ & 9750.0 & 2.76 \\
Testes & 43.9 & 0.109 \\
Other soft tissue & 1750.0 & 1.14 \\
Skeleton and teeth & 11200.0 & 151.0 \\
\hline Systemic total & 45100.0 & 250.0 \\
Whole body total & 46400.0 & 272.0 \\
\hline
\end{tabular}

(1) Includes skin and subcutaneous adipose tissue.

\begin{tabular}{|c|c|c|c|c|}
\hline Tissue/Organ & Autopsy weight (g) & ${ }^{238} \mathrm{Pu}(\mathrm{Bq})$ & ${ }^{239+240} \mathrm{Pu}(\mathrm{Bq})$ & ${ }^{241} \mathrm{Am}(\mathrm{Bq})$ \\
\hline$\overline{\text { Lungs }}$ & 1200.0 & 0.494 & 28.0 & 6.11 \\
\hline Pulmonary lymph nodes & 6.10 & 0.00340 & 0.181 & 0.0198 \\
\hline Liver & 1010.0 & 16.5 & 936.0 & 70.6 \\
\hline Kidneys & 196.0 & 0.0274 & 1.69 & 0.857 \\
\hline Spleen & 98.4 & 0.178 & 9.54 & 0.462 \\
\hline Smooth Muscle Organs & 1560.0 & 0.210 & 10.9 & 2.83 \\
\hline Striated Muscle ${ }^{(1)}$ & 28000.0 & 1.83 & 70.3 & 38.3 \\
\hline Other Muscle & 241.0 & 0.375 & 2.0 & 0.613 \\
\hline Skin ${ }^{(2)}$ & 17600.0 & $0.770^{(3)}$ & $42.1^{(3)}$ & $16.3^{(3)}$ \\
\hline Other soft tissue & 1310.0 & 0.122 & 6.44 & 1.87 \\
\hline Skeleton & 9640.0 & 21.3 & 1180.0 & 331.0 \\
\hline Systemic total & 59700.0 & 41.3 & 2260.0 & 463.0 \\
\hline Whole body total & 60900.0 & 41.8 & 2290.0 & 469.0 \\
\hline
\end{tabular}

(1) Reference man (ICRP-23).

(2) Includes skin and subcutaneous adipose tissue from Reference man (ICRP-23).

(3) Estimated on the basis of other whole body donations. No skin samples measured as of this report. 
TABIF 4

Summary of plutonium and americium contents in body organs of USTUR Case 0744 at death

\begin{tabular}{lcccc}
\hline Tissue/Organ & Autopsy weight $(\mathrm{g})$ & ${ }^{238} \mathrm{Pu}(\mathrm{Bq})$ & ${ }^{239+240} \mathrm{Pu}(\mathrm{Bq})$ & ${ }^{241} \mathrm{Am}(\mathrm{Bq})$ \\
\hline Lungs & 1930.0 & 1.35 & 75.0 & 17.6 \\
Pulmonary lymph nodes & 1.44 & 0.00510 & 2.06 & 0.503 \\
Liver & 2400.0 & 0.515 & 30.0 & 1.37 \\
Kidneys & 410.0 & $-{ }^{-3}$ & 0.139 & 0.0422 \\
Spleen & 550.0 & 0.0548 & 2.46 & 0.506 \\
Smooth Muscle Organs ${ }^{(1)}$ & 1360.0 & -- & 0.735 & 0.554 \\
Striated Muscle & 28000.0 & 0.102 & 3.03 & 0.963 \\
Other Muscle & 925.0 & - & 0.635 & 0.0416 \\
Skin (2) & 17600.0 & -- & 2.77 & 5.09 \\
Testes & $(1)$ & -- & 0.0568 & 0.0142 \\
Other soft tissue & 1470.0 & -- & 0.284 & 0.0398 \\
Skeleton & 10000.0 & 1.91 & 86.3 & 34.8 \\
\hline Systemic total & 62800.0 & 2.58 & 126.0 & 43.4 \\
Whole body total & 64700.0 & 3.94 & 203.0 & 61.5 \\
\hline (1) Referenceman & & & &
\end{tabular}

(1) Reference man (ICRP-23).

(2) Includes skin and subcutaneous adipose tissue from Reference man (ICRP-23).

(3) Individual samples too low to measure.

\begin{tabular}{|c|c|c|}
\hline Tissue/Organ & Autopsy weight (g) & Uranium $(\mu g)$ \\
\hline Lungs & 1390.0 & 327.0 \\
\hline Pulmonary lymph nodes & 13.0 & 13.1 \\
\hline Liver & 1290.0 & 3.20 \\
\hline Kidneys & 230.0 & 0.455 \\
\hline Spleen & 140.0 & 14.4 \\
\hline Smooth Muscle Organs & 2560.0 & 7.8 \\
\hline Striated Muscle $\mathrm{e}^{(1)}$ & 28000.0 & 11.3 \\
\hline Other Muscle & 731 & 0.584 \\
\hline Skin ${ }^{(2)}$ & 17600.0 & 4.18 \\
\hline Testes $^{(1)}$ & 35.0 & 0.154 \\
\hline Other soft tissue & 3360.0 & 4.11 \\
\hline Skeleton & 10300.0 & 44.3 \\
\hline Systemic total & 64200.0 & 90.5 \\
\hline Whole body total & 65600.0 & 431.0 \\
\hline
\end{tabular}

(1) Reference man (ICRP-23).

(2) Includes skin and subcutaneous adipose tissue from Reference man (ICRP-23). 
TABIF 6

Summary of uranium contents in body organs of USTUR Case 1028 at death

\begin{tabular}{|c|c|c|c|c|c|}
\hline Tissue/Organ & $\begin{array}{l}\text { Autopsy } \\
\text { weight }(\mathrm{g})\end{array}$ & ${ }^{234} \mathrm{U}(\mathrm{Bq})$ & ${ }^{235} \mathrm{U}(\mathrm{Bq})$ & ${ }^{238} \mathrm{U}(\mathrm{Bq})$ & $\begin{array}{l}\text { Total } \\
\mathrm{U}(\mu \mathrm{g})\end{array}$ \\
\hline Lungs & 1870.0 & 46.9 & 1.58 & 0.162 & 212.0 \\
\hline Pulmonary lymph nodes & 90.0 & 11.5 & 0.00161 & 0.00788 & 0.894 \\
\hline Liver & 1650.0 & 0.0741 & 0.00460 & $--^{(3)}$ & 0.581 \\
\hline Kidneys & 250.0 & 0.276 & 0.00830 & 0.00150 & 1.17 \\
\hline Spleen & 280.0 & 0.0450 & 0.0010 & 0.00156 & 0.253 \\
\hline Smooth Muscle Organs & 2850.0 & 0.0376 & 0.00587 & 0.0268 & 2.92 \\
\hline Striated Muscle ${ }^{(1)}$ & 28000.0 & 0.370 & 0.0578 & 0.264 & 28.8 \\
\hline Other Muscle & 720.0 & 0.0154 & 0.000846 & 0.00194 & 0.265 \\
\hline Skin ${ }^{(2)}$ & 17600.0 & 0.125 & 0.0188 & 0.0452 & 6.04 \\
\hline Other soft tissue & 1370.0 & 0.122 & 0.00668 & 0.00521 & 0.153 \\
\hline Ovaries & 12.0 & 0.0240 & -- & 0.0188 & 1.27 \\
\hline Skeleton & 7350.0 & 17.3 & 0.610 & 0.129 & 87.6 \\
\hline$\overline{\text { Systemic total }(\mathrm{Bq})}$ & 60100.0 & 18.4 & 0.714 & 0.477 & \\
\hline$(\mu \mathrm{g})$ & & 0.0803 & 90.1 & 38.8 & 129.0 \\
\hline Whole body total $(\mathrm{Bq})$ & 62000.0 & 76.8 & 2.30 & 0.67 & \\
\hline$(\mu \mathrm{g})$ & & 0.335 & 289.0 & 52.7 & 342.0 \\
\hline
\end{tabular}

(1) Reference man (ICRP-23).

(2) Includes skin and subcutaneous adipose tissue from Reference man (ICRP-23).

(3) Individual samples too low to measure.

\section{COLLABORATIVE RESEARCH PROJECTS}

The following collaborators have signed confidentialy agreements (USTUR PPM F106) or have Memoranda of Understanding on file that insures the protection of Registrant identities.

\section{University of Colorado}

Health Sciences Center

Denver, $\mathbf{C O}$

Dr. James Ruttenber

Objective: Conduct epidemiologic studies at the Rocky Flats Environmental Technology Site to explore important issues of measurement errors in quantifying exposures and their effects on estimates of risk in epidemiology studies. The USTUR will provide bioassay data in support of this project.

Oak Ridge Associated Universities Arvada, CO

Dr. Nancy Daugherty

Objective: Conduct case studies to compare 
in-vivo estimates of actinide body burdens with those measured, after death, by the USTUR in former Rocky Flats workers who were USTUR tissue donors. The USTUR will provide the radiochemical analytical data results from tissues of Rocky Flats donors in support of this project.

\section{Brookhaven National Laboratory \\ Brookhaven, NY \\ Dr. Casper Sun \\ University of Utah \\ UT \\ Dr. David Slaughter}

Objective: Plutonium deposition and retention in USTUR human placenta as determined by fission track analyses performed by the Brookhaven and Univeristy of Utah laboratories.

\section{University of Utah}

Salt Lake City, UT

Dr. R. Lloyd

Dr. Scott C. Miller

Objective: Microdosimetry and microdistribution of plutonium in human bone. The first series of Neutron-induced autoradiographs of Pu distribution in one USTUR bone sample and one from Mayak have been completed. Additional USTUR bone samples are currently under study.

\section{The Medical College of Ohio Toledo, $\mathbf{O H}$ \\ Dr. James Hardwick}

Objective: Molecular genetic studies of Registrant tissues. Writing a collaborative proposal to extend previous studies by determining the biological effects of alpha radiation on cell division cycle control and DNA repair genes determining whether increased DNA methylation is a dose dependent phenomena in Pu exposed individuals.

\section{Texas A\&M University}

College Station, TX

Dr. John Poston Sr.

Donald Halter (Graduate Student)

Objective: Biochemical analysis of USTUR skeletal tissue (cortical, cancellous and marrow) containing $\mathrm{Pu}$. This collaboration is for the doctoral thesis project of Donald Halter.

\section{Health Protection Bureau}

Human Monitoring Laboratory

Ottawa, Ontario CANADA

Dr. Gary Kramer

Objective: The USTUR is providing the materials for construction of a skeletal calibration phantom.

\section{Washington State University}

Department of Chemistry

Pullman, WA

Dr. Sue B. Clark

Objective: Preparation of external quality assurance/quality control samples for the USTUR radiochemistry protocols in known matrices.

\section{University of Pittsburgh \\ Graduate School of Public Health \\ Pittsburgh, PA}

Dr. Samuel E. Glover

Objective: The determination and subsequent comparison of calcium bone content from five USTUR whole body cases to determine the feasibility of using bone calcium content as a normalizing factor.

2nd Objective: Preparation of external quality assurance/quality control samples for the USTUR radiochemistry protocols in unknown matrices. 


\section{COMMITTEE APPOINTMENTS}

National Council of Radiation Protection (NCRP) Committee 57-17

Radionuclide Dosimetry Model for Actinide Wounds

\section{Faculty Member: John J. Russell}

Committee members prepare reports on each of their topical writing assignments. The USTUR report describes the biology, pathology, actinide retention and excretion in Registry wound and wound/inhalation cases. The report also contains a section on wound site pathology and tumor induction following Thorotrast injection.
International Agency for Research on Cancer (IARC)

World Health Organization

Evaluation of Carcinogenic Risk to Humans

Faculty Member: Dr. Mel R. Sikov

Committee members serve in working groups and prepare draft documents for sections on Perinatal Carcinogenesis and Intrauterine Metabolism. The resulting IARC Monograph: "Ionizing Radiation, Part 2: Some Internally Deposited Radionuclides" (Vol 78) 2001 ISBN 9283212789 , is currently in press.

\section{USTUR Faculty}

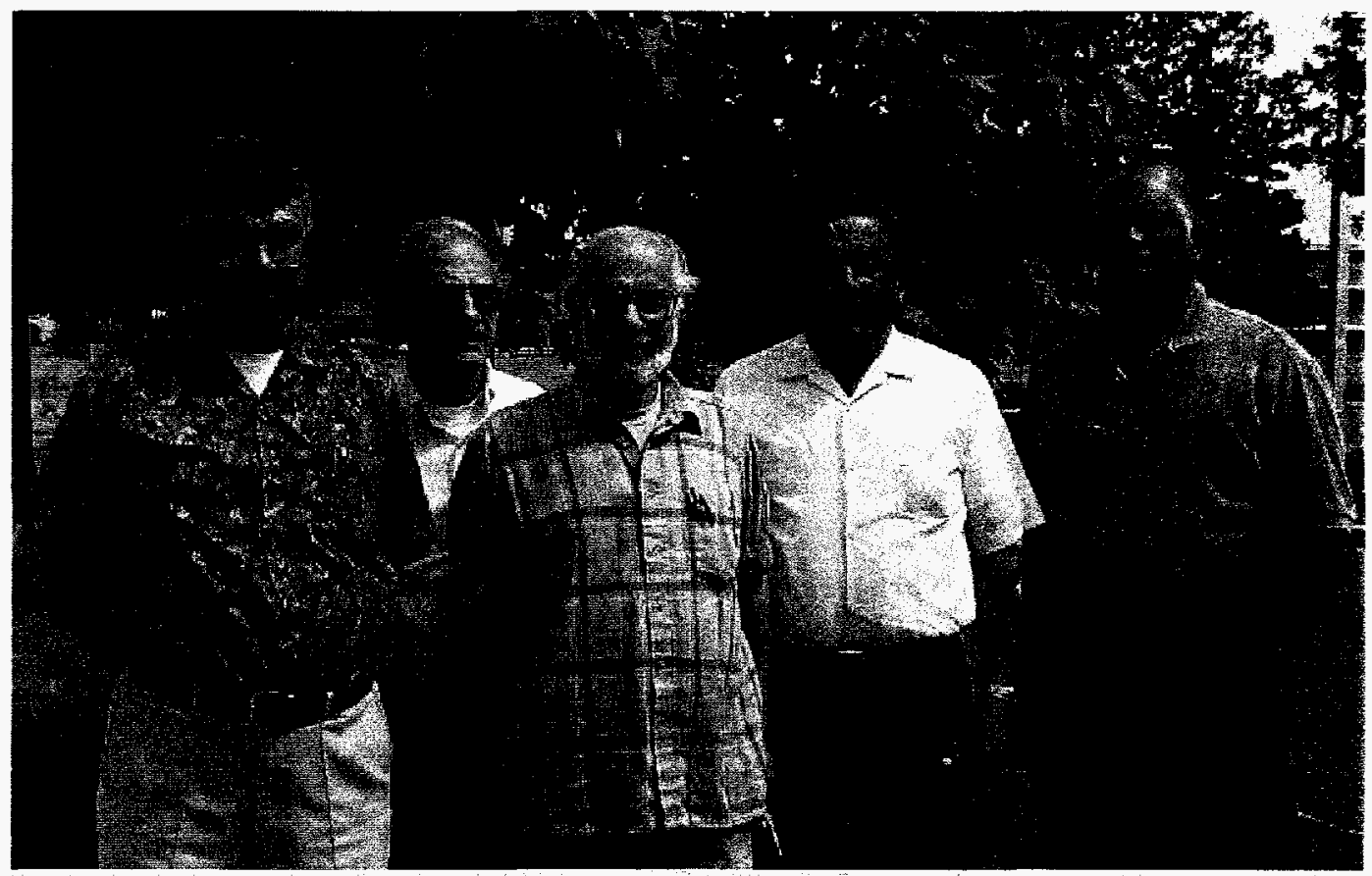

Above (1 to r): Gerald Dagle, Walt Wilson, Mel Sikov, Ronald Filipy, John Russell. Not Shown: Baruch Jacobson. 


\section{INFORMATION SYSTEMS}

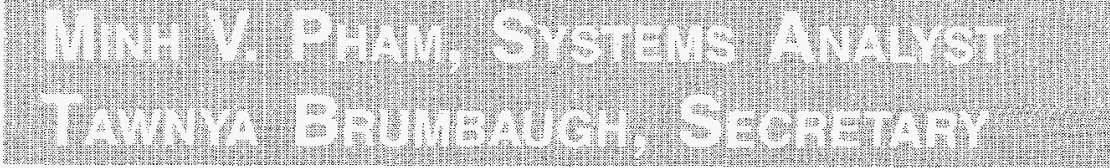

\section{USTUR Website}

The USTUR database and website have both undergone major changes. The website has had a complete overhaul. We started with an updated, animated logo and added new backgrounds, graphics, animations, updated and new information and links. The web page has grown to approximately $3600+$ links (Figure 4 ). The pages on the website not only tell the history of the USTUR, but what we are currently working on and what we are looking at for the future. There is a complete listing of our publications and abstracts, annual reports, descriptions of the database system and numerous pages and links to information about the NHRTR, the NRA, and how to contact us. The website gives a very in-depth look at what the USTUR is and what valuable and unique resources are available for possible research collaboration.

\section{Database}

Partially due to the contribution of both the Health Physics database table and the Medical database table, the USTUR database has also grown extensively, see Figure 5. We have completed entering health physics data on all deceased Registrants and have begun entering health physics data on the living Registrants with a projected completion timeline at the end of the project year 2001. As we add health physics data we are also entering all pertinent medical data and creating a summary for each Registrant to be included under the "Notes" section of the Medical database table.

Each of the database sections is quite extensive (Figure 5). Figure 6 shows an example of the admin database. Across the top of the form you will note that there are eight additional database tables and forms linked to the admin database. Each of these database table and forms (Figures 7-11) contain pertinent information about each Registrant and their history. You can access all information pertaining to a specific Registrant by clicking on the database tab at the top of the form. Lastly, there have been several administrative changes made to not only ensure user-friendly interface but to ensure complete data integrity.

\section{Our current World Wide Web address is: www.ustur.wsu.edu}


Figure 4

USTUR web page flow chart

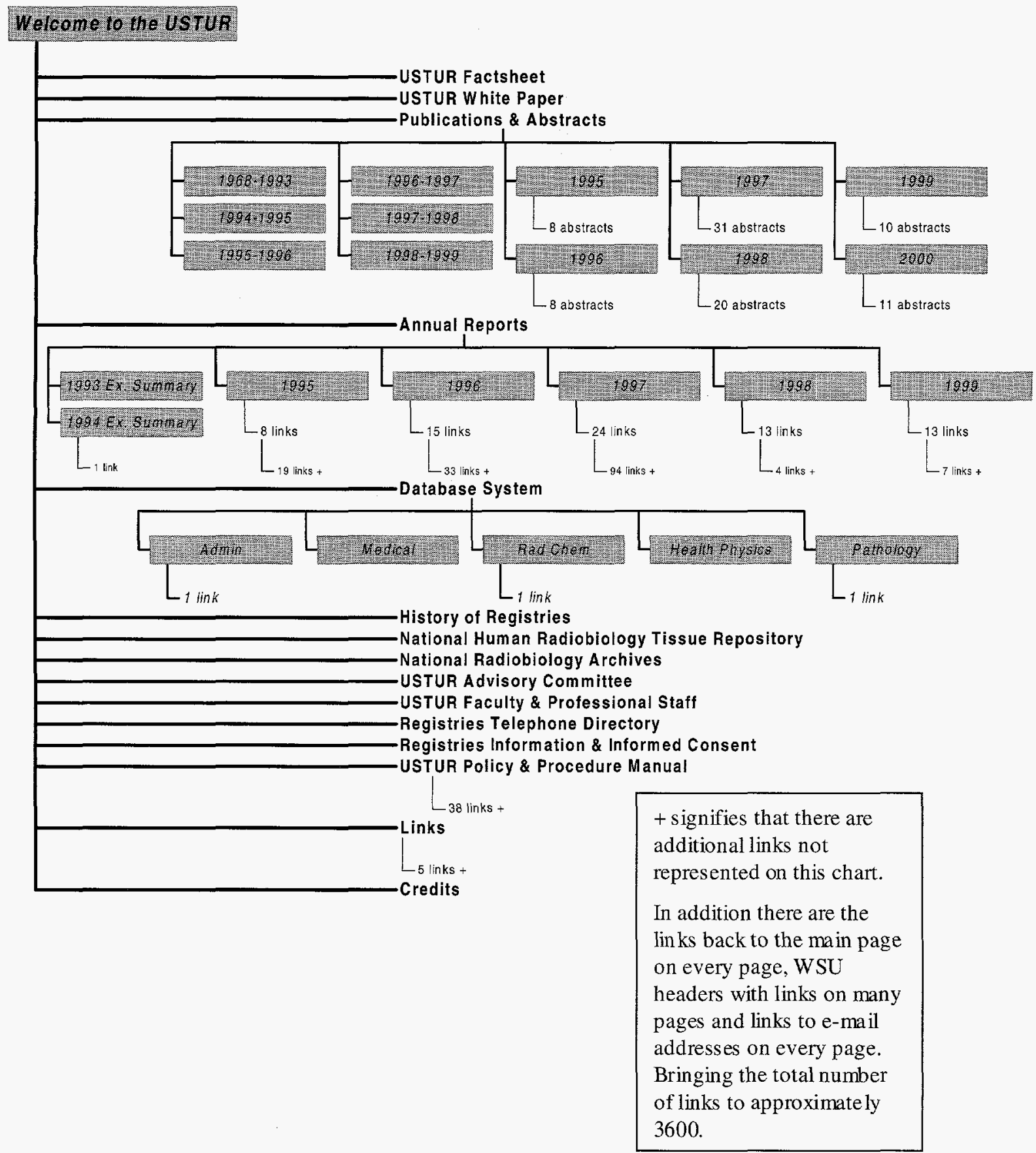


Figure 5

USTUR database flow chart

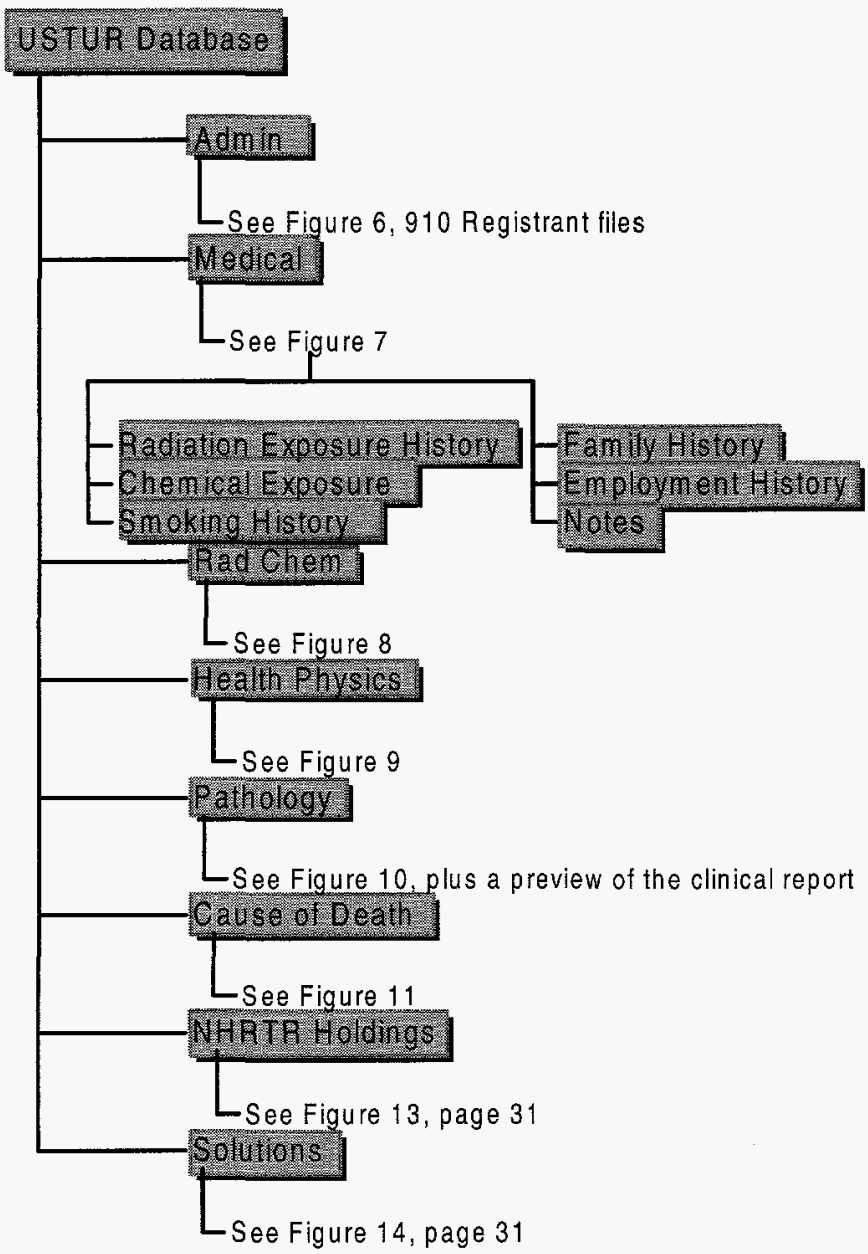

Figure 6

Admin form

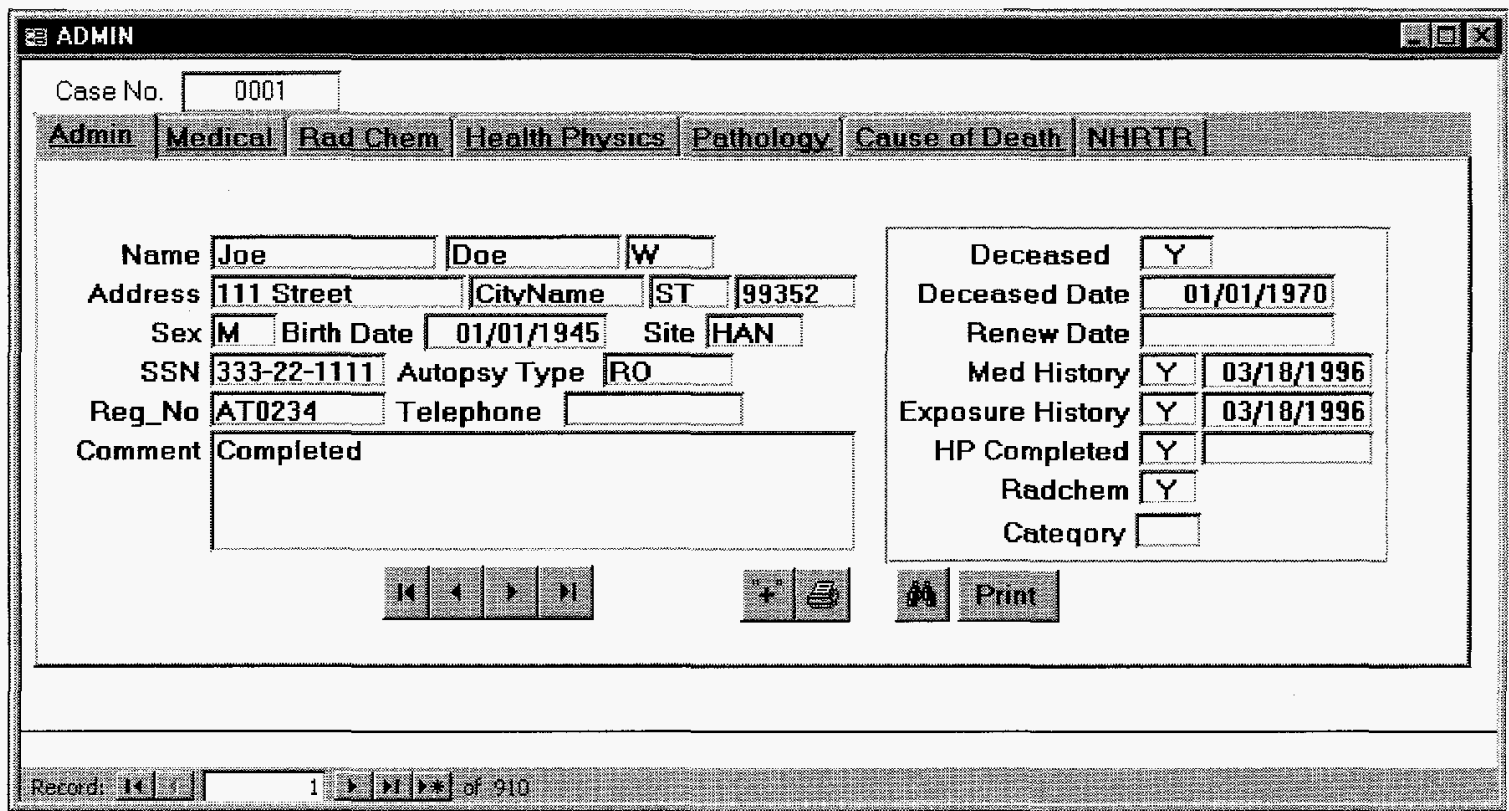




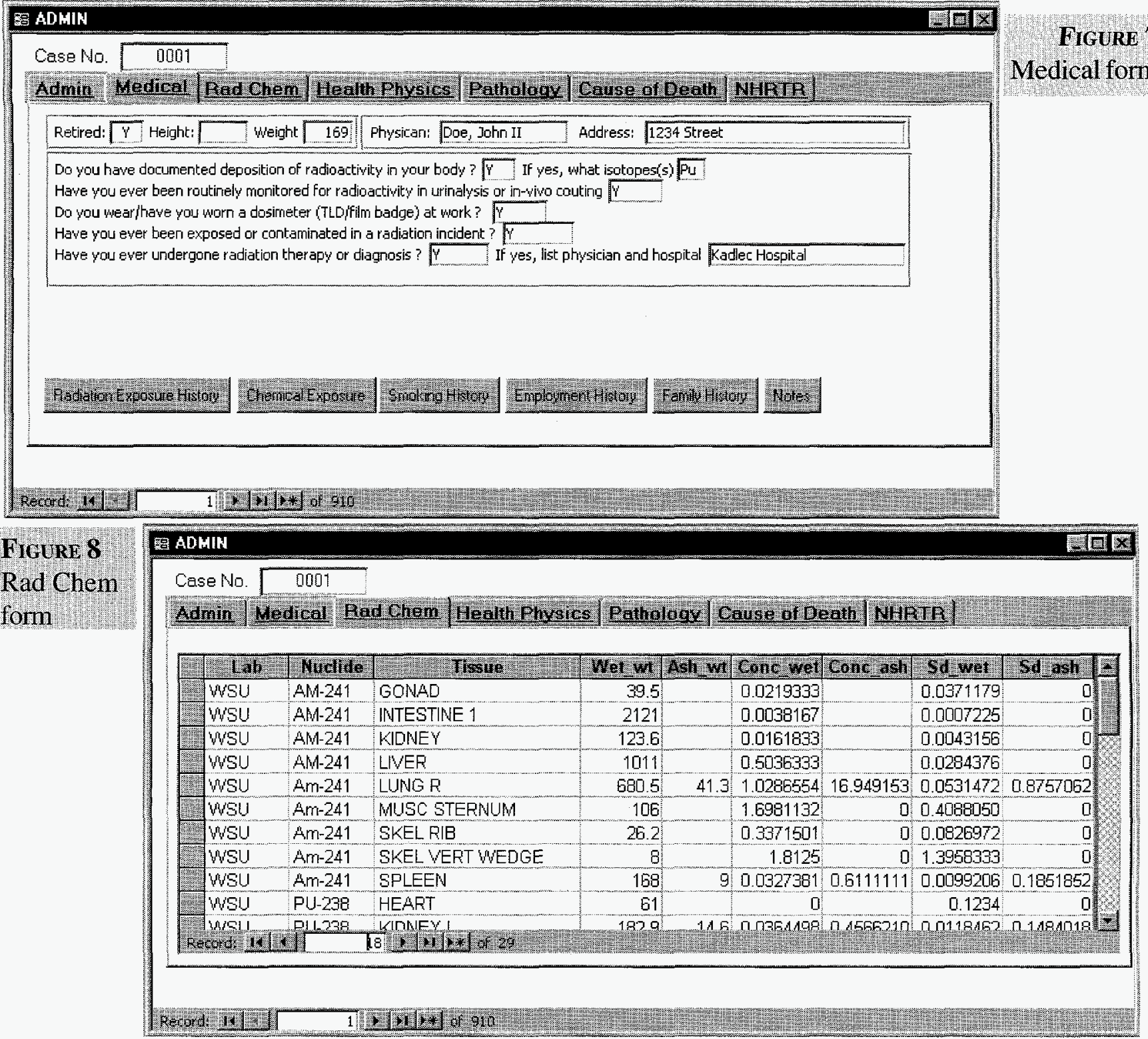

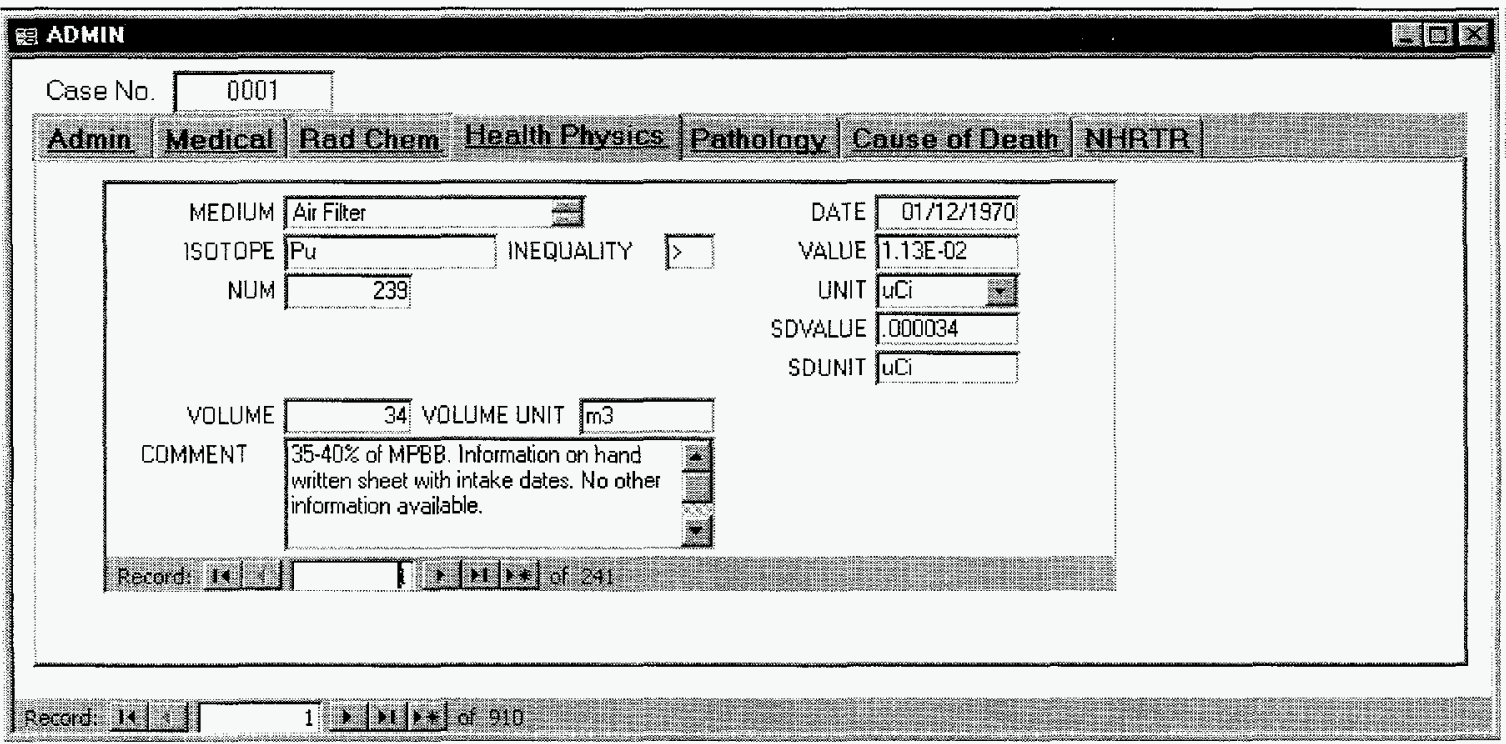

Figure 9

Health Physics form 
Figure 10

Pathology form

\section{ED ADHIN}

Case No. 0001

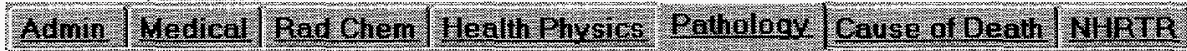

\begin{tabular}{|c|c|c|}
\hline Blood_chemistry & $\bar{Y}$ & Blood_hematolopy \\
\hline Chelation_treatments & $Y$ & Pulmonary_function \\
\hline Histopathology & $Y$ & Blocks \\
\hline Post-Mortem_yray & $Y$ & Dther_xray \\
\hline
\end{tabular}

Figure 11 Cause of Death form

\section{F⿸丆口}

Case No. 0001

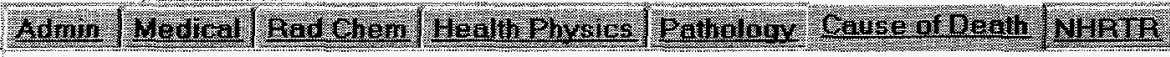

\begin{tabular}{|c|c|c|c|c|c|}
\hline & Soure: & Hent rorde & Prinary cause of dem & $1 \mathrm{Co} / \mathrm{cm}$ & Deareges code \\
\hline & D & 1 & Coronary Occlusion & 410.9 & \\
\hline & 0 & 2 & Mild fac al pheumonitis & 486 & \\
\hline & A & 3 & Benign retention cysts of kidneys & 753.19 & \\
\hline & A & 3 & Old healed myocardial infarction & 412 & \\
\hline & A & 3 & Old proststectomy for carcinoma & 185 & \\
\hline & D & 1 & Brain infarction & 434.9 & \\
\hline th & 0 & 2 & A.S.H.D. & 414.0 & \\
\hline tat & & & & & \\
\hline
\end{tabular}

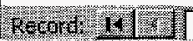

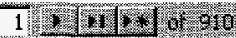




\section{RADIOCHEMISTRY OPERATIONS}

Director of Radiochemistry James T. Elliston

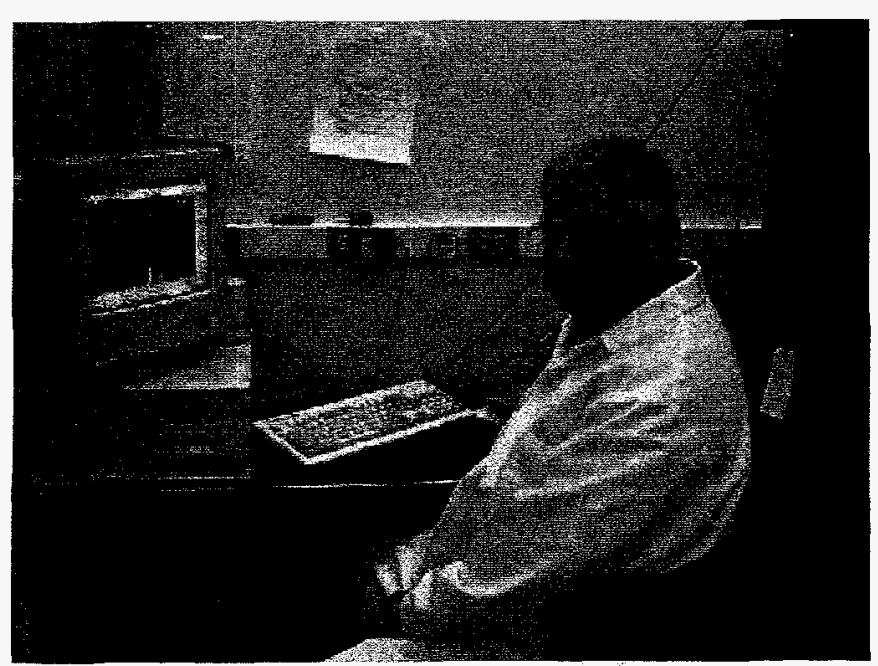

\section{Mission}

The mission of the Radiochemistry Project is to digest and analyze human tissues donated to the USTUR from workers occupationally exposed to americium, plutonium, thorium, and/ or uranium. The data from these analyses are used to confirm and/or modify exposure-modeling programs.

\section{Background}

The end of 2000 marked over 31 years of radioanalytical measurements of actinides in human tissues for the US Transuranium and Uranium Registries (USTUR) since its inception at HEHF in 1968. The radiochemistry program for the USTUR was transferred to Washington State University, Pullman, WA from Los Alamos National Laboratory in 1994 and continues to be housed at the Washington State University, Nuclear Radiation Center.
During the last seven years, the radiochemistry program has had great success in developing a quality laboratory, reducing the backlog of samples, developing new separation methods, publishing, and participating in the graduate and undergraduate educational process at Washington State University.

\section{Case Analyses}

Cases for sample analyses are divided into three categories: Routine Cases, Prioritized Routine Cases, and Whole Body Cases, based on the expected level of exposure from positive bioassay results.

\section{Routine Cases}

The expedited analytical protocol usually involves analyses of 4-5 tissue samples from each case for radionuclides suspected to be predominant in the samples. Samples typically include the lungs, pulmonary lymph nodes, liver, and 1-2 bone samples to establish an estimate of the body burden. The expedited protocol was performed on the following cases and reported during the project year:

Case 0279: A routine autopsy case from Hanford.

Case 0318: A routine autopsy case from Hanford.

Case 0348: A routine autopsy case from Hanford.

Case 0460: A routine autopsy case from Rocky Flats. 
Case 0719: A routine autopsy case from Los Alamos.

Case 0795: A routine autopsy case from Hanford.

Case 0814: A routine autopsy case from Hanford.

Case 0840: A routine autopsy case from Hanford.

Case 0740: A special case from Hanford, gallstones only.

Case 0793: A special case from Mound Lab, liver sample only.

\section{Prioritized Routine Cases}

Since the final quarter of 1997 , the USTUR radiochemistry program has been analyzing all routine cases using a prioritization scheme based on the whole body burden estimates from the expedited analytical protocol as recommended by the USTUR Advisory Committee. This procedure was initiated to prioritize, for future analyses, routine and whole body cases awaiting analysis by analyzing selected tissues from pending cases.

Four to five tissue samples from thirty-eight (38) routine cases have been completed between 1997 and January 31, 2001 for prioritization. Thus far only 12 of the cases evaluated have body burdens estimated at greater than 1000 $\mathrm{dpm}$ at death $(16.7 \mathrm{~Bq})$. Activities less than $1000 \mathrm{dpm}$ make precise measurement of the actinide content in other tissues difficult and the remaining analyses for these cases have been assigned very low priority.

\section{Whole Body Cases}

Reduction in the backlog of whole body cases continues to be one of the primary goals of the USTUR radiochemistry program. In keeping with this, additional whole body cases were completed or were being processed during this project year. Typically the tissues analyzed for a whole body case include half of the bones and all of the major organs. Cases completed or in process include:

Case 1028: A female Registrant from Oak Ridge was analyzed for isotopic uranium. Activity in the tissues of this Registrant was principally due to ${ }^{234} \mathrm{U}$ while the mass concentrations were due to ${ }^{235} \mathrm{U}$. This whole body case was originally analyzed by alpha spectrometry and the isotopic activities and concentrations were confirmed by high-resolution alpha spectrometry and ICP-MS. This case was reported during this project year.

Case 0744: A male whole body Registrant from Rocky Flats was analyzed for plutonium and americium. This case was reported during the year 2000

Case 0425: A male whole body Registrant from Rocky Flats that is in the process of being analyzed for americium, plutonium and natural uranium. Data entry and final reporting will be completed during this project year. Two replacement samples are awaiting the muffle ashing stage.

Case 0503: A male whole body Registrant from Rocky Flats was started as an initial survey of five samples.

Case 0635: A male whole body Registrant from Los Alamos is being prepared for muffle ashing. Five samples are in the dissolution stage for an initial survey.

Case 0680: A male whole body Registrant from Los Alamos was started as an initial survey of six samples. The survey samples are in the digestion phase. 
Case 0682: A male whole body Registrant from Mound Laboratories was exposed to ${ }^{238} \mathrm{Pu}$ as a result of a glove box explosion. Preliminary results show that there are several dpm of ${ }^{238} \mathrm{Pu}$ per gram of bone ash. This case is in the muffle ashing phase.

Case 0706: A male whole body Registrant from Rocky Flats was started as an initial survey of five samples.

\section{Graduate/Undergraduate Student Involve- ment}

The USTUR radiochemistry program has been actively involved in the education of undergraduate and graduate students since its transfer to Washington State University. This is evident in the number of past students associated with the program, degrees granted, student publications, theses, and presentations at national and international meetings. At present, the USTUR supports the research of PhD. candidate James T. Elliston into the distribution of natural uranium in human tissues in a whole

\section{Figure 12}

Breakdown of samples analyzed by WSU

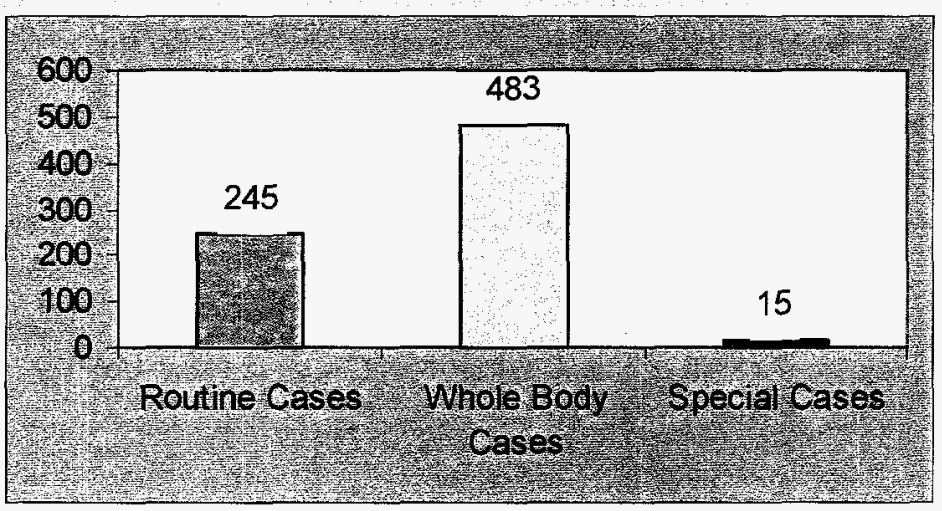

The expedited analysis protocol for Routine cases typically involve 4-6 samples analyzed for plutonium and americium. Special Cases typically have 2-6 samples and are for special purpose (i.e. uranium in urine, $\mathrm{Cm}$ in tissues). Whole Body Cases, on the otherhand, generally have 120 to 140 samples. body donor to the USTUR, analyzed by recovery corrected kinetic phosphorescence analysis. In addition, Rosara Payne an undergraduate student in chemistry at Washington State University completed research into the Optimization and Characterization of a Sulfate Based Electrodeposition method for Alpha Spectrometry of Neptunium and Curium (In Press, Journal of Radioanalytical and Nuclear Chemistry) in conjunction with the USTUR radiochemistry program under the direction of Dr. Samuel E. Glover.

\section{RADIOCHEMISTRY LABORATORY}

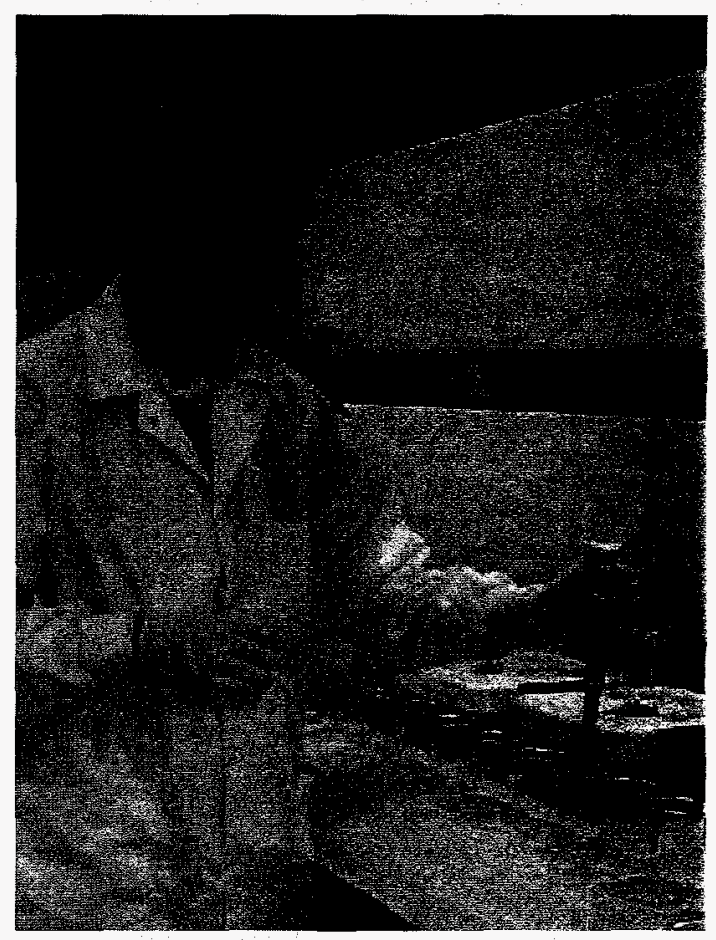

(Above) Dorothy Stuit in the radiochemistry laboratory doing column seperation work. 


\section{NATIONAL HUMAN RADIOBIOLOGY}

TISSUE REPOSITORY

\section{Donor Statistics}

During this reporting period, the NHRTR arranged autopsy services and tissue acquisition for 7 Registrants who died during the period; six were routine autopsies and one was a whole body donor. The NHRTR dissected, weighed, bagged, and shipped over 200 tissue samples from 6 whole body donors and 7 routine autopsy cases to the radiochemistry laboratory in Pullman.

The whole body donor case received this year, USTUR Case 0635, was also one of Dr. George Voelz' long-term follow-up cases last reported on in: 50 Years of Plutonium Exposure to the Manhattan Project Plutonium Workers: An Update. Health Phys. 73, 1997. G. Voelz et al. He was \#9 in the LANL study. Due to the vast amount of information available on this case, radiochemical analysis of the tissue samples obtained from this Registrant was expedited.

\section{Laboratory Inventory}

A detailed inventory of the NHRTR freezers was started to locate, identify, and quantify the samples included in the computerized listing of tissue samples maintained by the NHRTR. A table entitled NHRTR Holdings was created in Microsoft Access and linked to the Administrative database table. The table includes Registrant case number, freezer number, room location, type of tissue, ICD9 coding, and comment section, see Figure 13. Incorporating the
NHRTR Holdings sample inventory into the Administrative database will allow the data to be easily accessed and available when potential collaborators and scientific investigators request samples for scientific research.

Additionally, the NHRTR has approximately 1200 boxes containing acid-dissolved tissue solutions processed by LANL and WSU from USTUR Registrants and control cases. A table was created in Microsoft Access entitled Solutions and linked to the Administrative database, see Figure 14. The table includes ID number, box number, solution, and Registrant case number. Each individual solution box was inventoried and labeled with the carton ID, case number and solution(s) included (i.e. spleen, liver, ribs etc.). These acid solutions are essential to the program and are used primarily for analytical rerun purposes. If analytical data for an individual case looks a little suspect, the USTUR would request a rerun from the acid solutions to validate the results. Additionally, these acid solutions can be used for further studies regarding trace metal analysis. It is anticipated that the inventory will be completed and the comprehensive computerized list added to the USTUR database by the end of project year 2001. 
Figure 13

NHRTR Holdings form

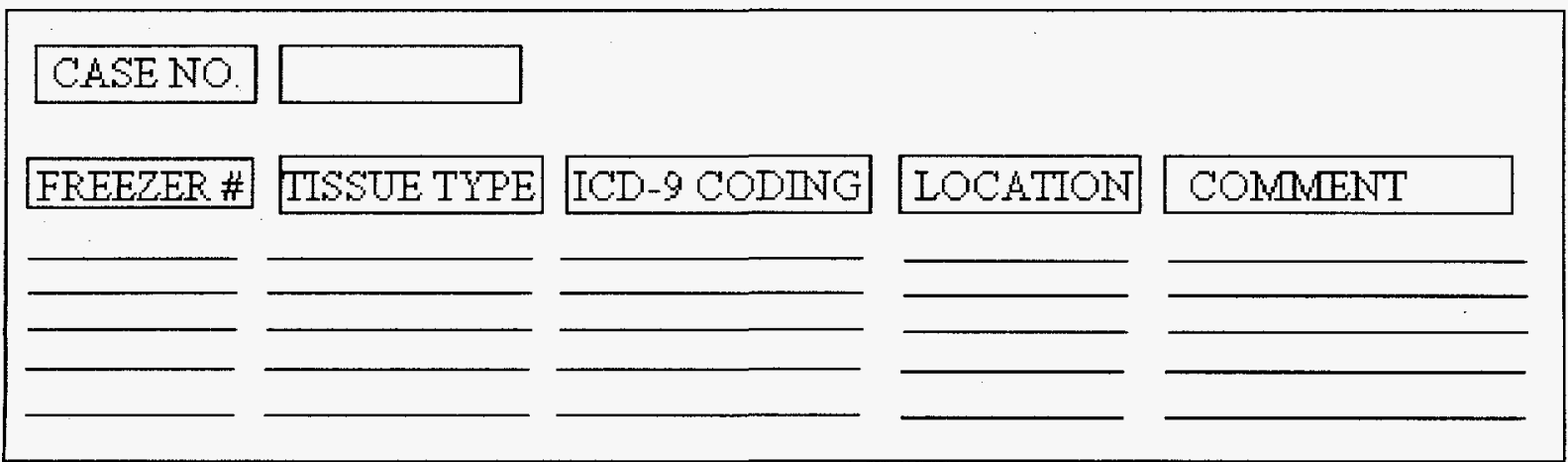

USTUR WHFTF HOLDINGS FOFM

\section{Figure 14}

Sample Solution form

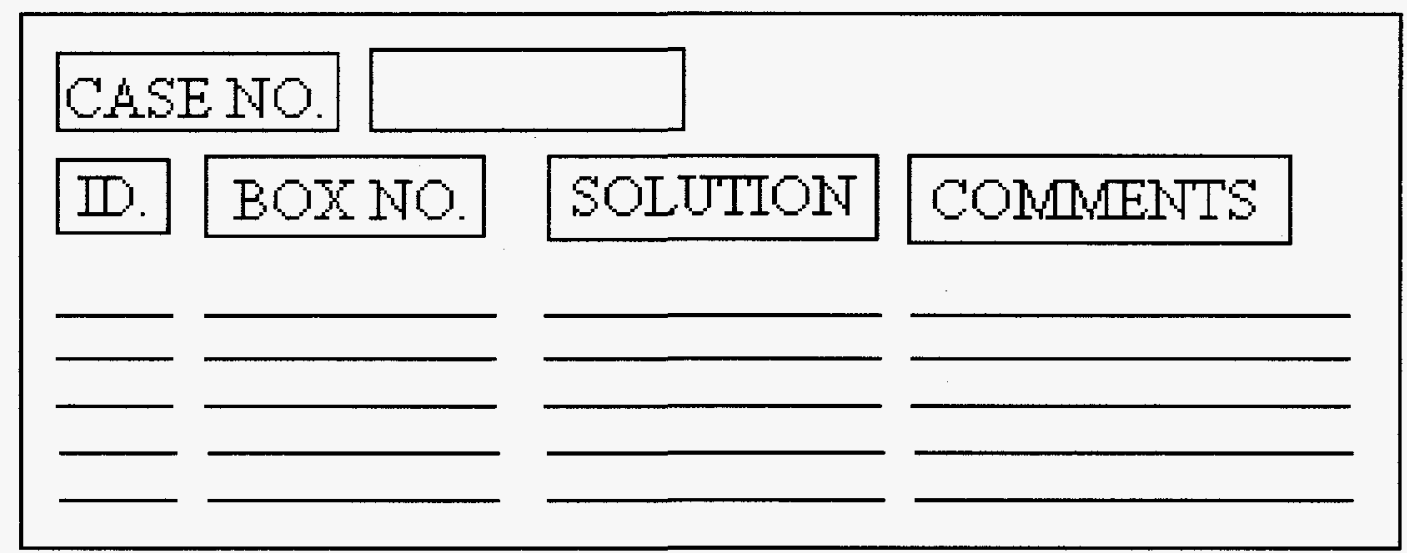

USTUR SAMPLE SOLUTIOH FORM 


\section{NATIONAL RADIOBIOLOGY ARCHIVES}

\section{Grant Renewed}

During this fiscal year, a continuation proposal to operate the National Radiobiology Archives was submitted to the Department of Energy. The Cooperative Agreement No. DE-FC0396ER62213, "Operation of the National Radiobiology Archives", was approved and funded for an additional three years. The current grant term is January 1, 2000 -December $31,2003$.

\section{Program Summary}

The NRA is an archival program that was started in 1989 and whose original mission was to collect, organize, catalog data, lab notebooks, and animal tissue specimens from government (DOE and its predecessor agencies) sponsored radiobiology life-span studies performed at various national labs and university facilities since the 1940's. Thus, these valuable archived records, histopathology slides and paraffin embedded tissue blocks are stored and maintained in a centralized facility and are available for additional future research and or analyses if and when needed. Although these studies were performed over many years and at different laboratories with differing data managing systems, the NRA has translated them into a more convenient set of relational database tables, which can be distributed to interested individuals following a written request.

Since transfer of the NRA to WSU, the USTUR has actively promoted and publicized the use of these materials by outside investigators in addition to utilizing NRA data and ma- terials to facilitate its long standing stated goal of validating animal data for use with human biokinetic models and safety standards development.

\section{New Data Available}

During the past FY, the NRA has received via Dr. Charles Watson, the database files from Argonne National Laboratory (ANL) that describe the rodent and beagle dog studies performed in the ANL Division of Biology and Medicine. The beagle data are from the two primary dog studies performed in the Janus program, one continuous exposure and one protracted / terminated study.

\section{Public Requests}

A number of inquiries and formal requests for NRA materials and or data have been received from outside investigators during this project yeat and since our last annual report, one manuscript written by a USTUR adjunct faculty member using data from the NRA has been submitted for publication in the open peer-reviewed literature:

IARC Monographs on the Evaluation of Carcinogenic Risks to Humans. 78, Ionizing Radiation, Part 2, Internal Sources. Lyon, France, June 2000 (submitted). The sections entitled (a) Studies on Cancer in Experimental Animals and (b) Other Data Relevant to an Evaluation of Carcinogenicity and its Mechanisms were prepared by M. R. Sikov. 
In addition to the above-mentioned studies, several individuals seeking NRA data and/or information have contacted the Registries during the past year. Several of the more significant requests are described briefly below:

Mr. Julius P. Arocha, Mission Viejo, CA, contacted the NRA seeking information on experimental animal data contained in the archives.

Mr. Christopher Jolley, a graduate student at Oregon State University, contacted the NRA concerning radioactive fallout study information possibly contained in Dr. Miriam Finkel's files.

Dr. Enachescu of Romania e-mailed the Registries and asked for information on experimental animal study data maintained in the NRA.

*This work was supported by the Office of Biological and Environmental Programs/Department of Energy via grant number DE-FC0396ER62213 to Washington State University.

\section{DATA MANAGEMENT}

The USTUR database contains a wealth of information regarding the exposure histories and medical histories of former nuclear workers who had documented exposures to uranium, plutonium, americium, and other actinide elements. There is also information about body contents of those elements, measured during life by bioassays and measured after death by radiochemical analyses of donated tissue samples. During the past two years, the emphasis has been toward making those data useable by scientists other than USTUR staff members. There has been an extensive quality assurance effort directed toward verification of database entries by comparing them to original data in the paper files and the format of the database has been modified to facilitate queries for specific data. These tasks, described in the USTUR Annual Report for February 1, 1999-January 31, 2000, are well underway with estimated completion dates during this project year.
The USTUR Radiochemistry database table contains the analytical results from tissues collected at autopsy of approximately 250 nonwhole body donors who worked with plutonium and americium and had varying amounts of systemic depositions of those actinides. One problem that confronts the users of these data is that of estimating a total skeletal content of the actinides based on the contents of the selected bones collected at autopsy. Typically, the bones collected at an autopsy of a non-whole body donor may include the sternum, a clavicle, one or both patellae, a rib, and a vertebral wedge cut from within the abdominal cavity. Based on the analyzed skeletons of whole body donors, a number of relationships between the actinide content of those individual bones and that of the entire skeleton have been determined. Most of those relationships have limitations, for example, a single patella was determined by Lynch et al. (J. Rad. Prot. 8:67-76; 1988 ) to contain $0.33 \%$ of total skeletal pluto- 
nium and $0.37 \%$ of total skeletal americium. Thus, the patella would be a simple and convenient bone upon which to base the skeletal contents; however, the patellae became part of the autopsy protocol relatively recently and they were not collected in the first 100 , or so, autopsies performed for the USTUR. Another method of extrapolating from actinide contents in individual bones to those of the entire skeleton involved bone-to-skeleton concentration ratios that were described in the USTUR Annual Report (October1, 1994-September 30, 1995). These were concentration ratios based on wet weight or on ashed weight; therefore, there were up to ten ratios for each case that could result in ten, separate estimates of the skeletal content of each nuclide and the estimates were not necessarily consistent for a given case. The following is a brief description of a newly developed model that avoids the problems associated with preceding models.
Several statistical methods for estimating skeletal actinide concentrations from individual bone concentrations were considered. Least squares regression was chosen because expected bias and precision are smaller using the least squares estimator compared to the ratio of sample means or the mean of sample ratios. Furthermore, the simple regression estimator is easily extended to multiple regression for estimating the skeletal concentration from the concentrations in a group of bones. A regression relating the skeletal concentrations to individual bone concentrations from eight whole body donations was used for each of the bones collected at autopsy. Figure 15 shows the regression that was used for wet concentrations of ${ }^{239+240} \mathrm{Pu}$ in the clavicles and skeletons of the eight cases. The regression coefficients and goodness of fit diagnostics for the clavicular regression as well as the other four bones usually collected at autopsy are given in Table 7 .

\section{TABLe 7}

Regression coefficients and goodness of fit diagnostics for wet concentrations of $239+240 P u$

\begin{tabular}{llll}
\hline & & Mean & Maximum \\
Bone & Regression & Square & Prediction \\
\hline
\end{tabular}

$\begin{array}{llll}\text { Clavicle } & 1.01 & 2.13 & 4.44 \\ \text { Ribs } & 0.709 & 4.43 & 6.64 \\ \text { Sternum } & 0.990 & 3.81 & 6.41 \\ \text { Patella } & 1.31 & 3.22 & 5.59 \\ \text { Vert. Wedge } & 0.797 & 6.13 & 7.73\end{array}$

The mean square error is the sum of the squared deviations of the observed skeletal concentrations predicted by the regression model, divided by error degrees of freedom. The maximum bound on the error of prediction is the largest value of the half-width of the simultaneous $95 \%$ prediction interval. In Figure 15, for example, the maximum vertical distance from the predicted line to the upper (or lower) bound is 4.44 . An estimate of the skeletal concentration could be obtained from a clavicular concentration of
$10 \mathrm{~Bq} / \mathrm{kg}$ of ${ }^{239+240} \mathrm{Pu}$ as follows:

Skeletal concentration $=$

$$
1.01(10 \mathrm{~Bq} / \mathrm{kg})=10.1 \pm 4.44 \mathrm{~Bq} / \mathrm{kg} \text {. }
$$

If the analytical results from more than one bone are available, an improved estimate of the skeletal concentration may be possible by using multiple regression methods. Coefficients to be used in the model based on the claviclular, rib, and patellar concentrations are shown in Table 8. 
TaBle 8

Multiple regression coefficients and goodness of fit diagnostics for wet concentrations of ${ }^{239+240} \mathrm{Pu}$ in the clavicle, ribs, and patella

\begin{tabular}{lccll}
\hline Clavicle & Ribs & Patella & $\begin{array}{l}\text { Mean } \\
\text { Square } \\
\text { Error }\end{array}$ & $\begin{array}{l}\text { Maximum } \\
\text { Error } \\
\text { Bound }\end{array}$ \\
\hline 0.599 & 0.269 & 0.0446 & 0.655 & 2.89 \\
\hline
\end{tabular}

For a case where each bone had a plutonium concentration of $10 \mathrm{~Bq} / \mathrm{kg}$, the skeletal concentration would be calculated as follows:

$$
\begin{array}{ll}
\text { Clavicle } & 0.599(10 \mathrm{~Bq} / \mathrm{kg})=5.99 \\
\text { Ribs } & 0.269(10 \mathrm{~Bq} / \mathrm{kg})=2.69 \\
\text { Patella } \quad 0.0466(10 \mathrm{~Bq} / \mathrm{kg})=0.446 \\
\text { Skeletal Concentration }(\mathrm{sum})=9.13 \pm 2.89 \\
\text { Bq/kg. }
\end{array}
$$

The small coefficient for the patella in the example above is a consequence of correlation among the measured bone concentrations. This phenomenon, known as multicollinearity, occurs when two or more predictor variables (i.e. bone concentrations) are highly correlated.

Regression coefficients and goodness of fit diagnostics have been calculated for single bones (as in Table 7) and for two, three, four, or five bones that are (or might have been) collected at autopsy, for wet and ashed weight concentrations of ${ }^{238} \mathrm{Pu},{ }^{239+240} \mathrm{Pu}$, and ${ }^{241} \mathrm{Am}$. In general, the coefficients for wet bone concentrations have smaller prediction errors associated with them than do the coefficients for ashed bone concentrations. That, coupled with the fact that ashed bone weights were not measured in approximately 90 of the earlier USTUR cases, means that the model based on wet weight concentrations will be the model of choice. The model can be expanded to include other bones and nuclides other than plutonium and americium as soon as sufficient analytical data from whole bodies containing those nu- clides become available.

This model will be used to estimate actinide skeletal concentrations from the bone sample concentrations of the approximately 250 nonwhole body donors autopsied by the USTUR. Skeletal actinide concentrations will then be included with the analytical results of other collected organs in a working Radiochemistry table in the USTUR database for use by research collaborators. This model was described in detail in a manuscript submitted for publication in the scientific literature. 


\section{Figure 15}

Regression of skeletal ${ }^{239+240} \mathrm{Pu}$ concentrations against clavicular concentrations from eight whole body donors to the USTUR

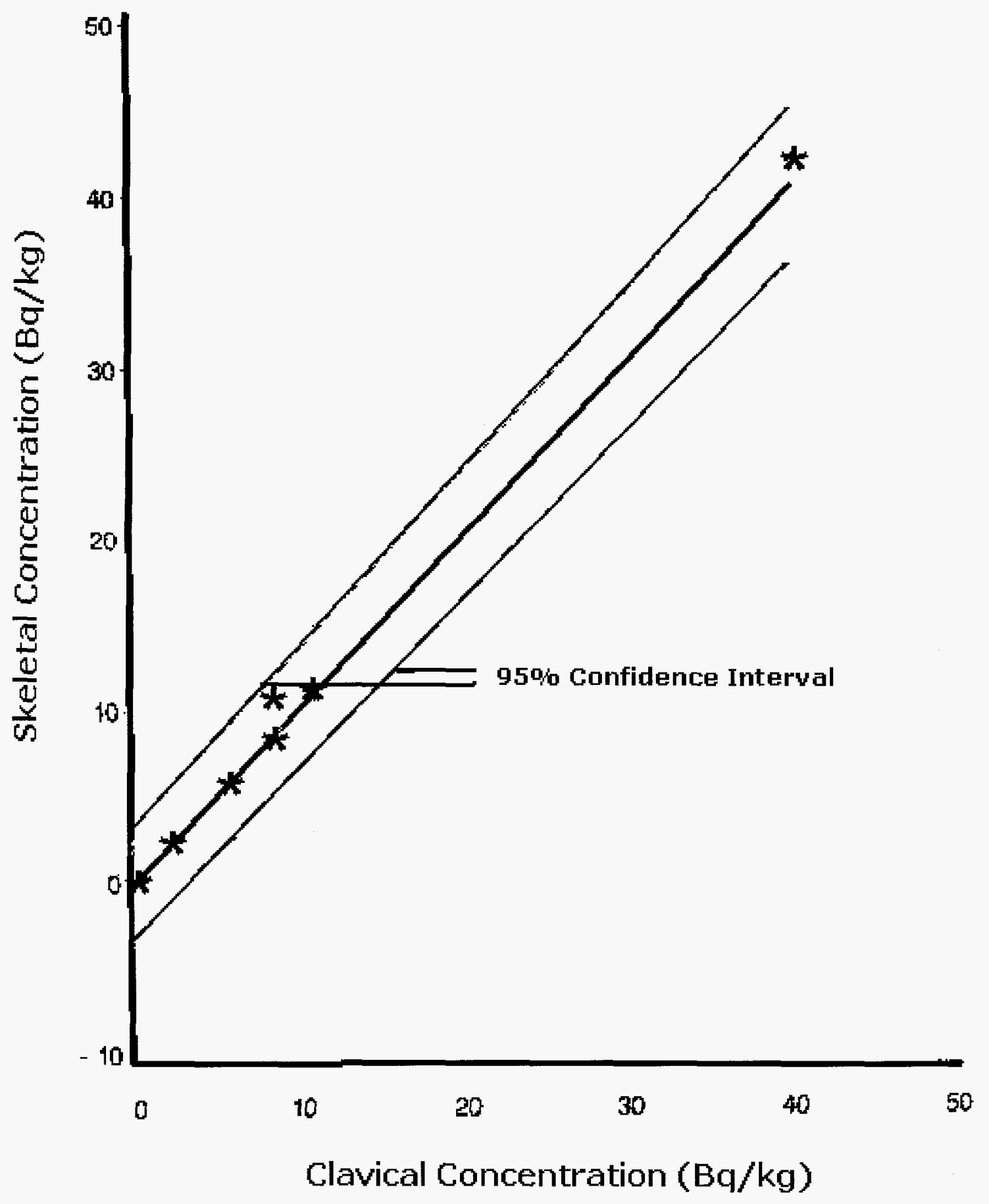




\section{THE EFFECT OF CHELATION THERAPY ON URINARY EXCRETION OF PLUTONIUM IN A USTUR WHOLE BODY DONOR}

The results of the radiochemical analyses of tissues from USTUR Case 0269 were summarized elsewhere in this report. As indicated, this worker suffered a very large intake of a relatively soluble form of plutonium and he received chelation therapy for nearly four years after the incident with collection of urine samples for more than 20 years after the incident. Table 9 of this report contains a summary of the plutonium urinary excretion data as it correlated with chelation therapy, first with calcium ethylenediaminetetraacetic acid ( $\mathrm{Ca}$ EDTA) and later with calcium diethylenetriaminepentaacetic acid ( $\mathrm{Ca}$ DTPA).

The summary of data leads to some interesting observations about the effect of chelation therapy in this case. As a chelating agent, the Ca-EDTA appeared to be relatively effective, especially during the first six weeks after exposure when its administration resulted in approximately a seven-fold increase in urinary excretion compared to times at which none was administered. Orally administered Ca-EDTA (days 46-51 and 98-102) was not effective in increasing urinary excretion of plutonium and, when given together with intravenous (IV) Ca-EDTA appeared to have approximately the same effect as that administered IV, only.

Ca-DTPA appeared to enhance urinary excretion of plutonium; however, it was not admin- istered until nearly 2.5 years after exposure and, by that time, plutonium available for chelation had been substantially reduced. Although not shown in the data summary, the effect of CaDTPA appeared to last longer after cessation of administration; excretion of plutonium remained at a relatively high level for one to two days after the last treatment. This effect was not obvious in the Ca-EDTA data.

Fecal samples were collected regularly during the first few months and sporadically thereafter. Nearly $13 \mathrm{kBq}$ of plutonium were excreted in feces during the first five days after exposure, clearly a result of mucuciliary clearance of plutonium from the lungs with passage into the digestive tract. Fecal excretion of plutonium diminished rapidly during the first two weeks after exposure and chelation therapy with either Ca-EDTA or Ca-DTPA had no obvious effect. 
TABLE 9

Urinary excretion of ${ }^{239+240} \mathrm{Pu}$ after an acute exposure incident followed by chelation therapy

Days after No. of

Exposure

Treatments

IV $(\mathrm{g})$

Urinary

Ca-EDTA

$\begin{array}{lc}1-6 & 10 \\ 7-12 & 0 \\ 13-17 & 10 \\ 18-21 & 0 \\ 22-26 & 9 \\ 27-29 & 0 \\ 30-39 & 18 \\ 40-45 & 0 \\ 46-51 & 6 \\ 52-56 & 0 \\ 57-65 & 14 \\ 66-77 & 0 \\ 78-85 & 16 \\ 86-97 & 0 \\ 98-102 & 5 \\ 103-104 & 0 \\ 105-116 & 10 \\ 117-139 & 1 \\ 140-151 & 10 \\ 152-160 & 0 \\ 161-165 & 5 \\ 166-175 & 0 \\ 176-179 & 4 \\ 180-869 & 2\end{array}$

10

35.6

0

10

10

2.65

23.6

0

9

0

18

0

6

0

14

0

16

0

5

0

10

1

10

0

5

0

48

22

9

3.79

20.9

18

3.37

21.1

12

3.08

3.14

1.70

14

8

11.8

16

3.29

10.1

1.72

40

1.34

1.56

17

$\begin{array}{cl}19 & 5.82 \\ 2 & 2.09\end{array}$

19

19

7.71

2.72

6.88

2.35

6.03

0.52

Ca-DTPA

$869-875$

10

2.8

11.9

$876-930 \quad 0$

11.4

4.92

7.93

964-1030 0

$1031-1187 \quad 22$

$1188-1212 \quad 0$

$1212-1235 \quad 8$

$1235-1637 \quad 1$

$1638-1642 \quad 3$

$1654-5000 \quad 0$

22

3.03

2.57

0.322

3.45

0.309

5.12

0.0964

0.0168 


\section{PUBLICATIONS AND PRESENTATIONS}

February 1, 2000 to January 31, 2001.

Abstracts are included in Appendix $A$ of this report.

\section{Published:}

Brooks, A.L. and S. Bao. Induction and Repair of HZE Induced Cytogenetic Damage. Published in proceedings of the 1st International Workshop on Space Radiation Research and 11 th Annual NASA Space Radiation Health Investigators' Workshop. Arona, Italy, May 27-31, 2000. NASA, Washington, DC. (Abstract) Pp. 35-36; 2000.

Ehrhart, S.M. and R.E. Filipy. United States Transuranium and Uranium Registries Newsletter, Issue \#7. USTUR-0169-00; 2000. College of Pharmacy, Washington State University, Richland, WA.

Ehrhart, S.M. and R.E. Filipy. United States Transuranium and Uranium Registries Annual Report: February 1, 1999 - January 31, 2000. USTUR-0156-00; 2000. College of Pharmacy, Washington State University, Richland, WA.

Filipy, R.E., J.R. Alldredge, S.E. Glover, V.F. Khokhryakov, K.G. Suslova, E.E. Aladova and V.V. Vostrotin. Combination of the Actinide Analysis Data of Two Human Tissue Analysis Programs: Triumphs and Problems. Published in Proceedings of the 2nd International Symposium on Chronic Radiation Exposure: Possibilities of Biological Indication. Chelyabinsk, Russian Federation. March 1416, 2000. Urals Research Center for Radia- tion Medicine, Chelyabinsk, Russian Federation. (Abstract) Pp. 87-88; 2000.

Filipy, R.E., V.F. Khokhryakov, K.G. Suslova and E.E. Aladova. A Collaborative Research Project Involving the Human Tissue Analysis Programs of the United States and the Russian Federation. Published in Proceedings of the Topical Meeting on Radiation Protection for our National Priorities; Medicine, the Environment and the Legacy. Spokane, WA, September 17-21, 2000. American Nuclear Society, La Grange Park, IL. Pp. 3-9; 2000.

Kathren, R.L. Scientific and Administrative History of the USTUR. Technology 7(24):165-180;2000.

Jacobson, B. Cataracts in Retired Workers with Transuranic Exposure Histories. Published in Proceedings of the Topical Meeting on Radiation Protection for our National Priorities; Medicine, the Environment and the Legacy. Spokane, WA, September 17-21, 2000. American Nuclear Society, La Grange Park, IL. (Abstract) Pp. 53; 2000.

Kathren, R.L. and J.J. Russell. The U. S. Transuranium and Uranium Registries: What the Human Data Have Shown. Published in Proceedings of the Topical Meeting on Radiation Protection for our National Priorities; Medicine. the Environment and the Legacy. Spokane, WA, September 17-21. 2000. American Nuclear Society, La Grange Park, IL. Pp. 75$82 ; 2000$.

Khokhryakov, V.F., K.G. Suslova, E.E. Aladova, V.V. Vostrotin, A.V. Efimov, R.E. 
Filipy, S.E. Glover, J.R. Alldredge and T. Woods. Progress Report \#8 (Final), Project 2.1: Metabolism and Dosimetry of Plutonium Industrial Compounds. Richland, WA: College of Pharmacy, Washington State Univerity. USTUR-0155-00; 2000.

Khokhryakov, V.F., K.G. Suslova, R.E. Filipy, J.R. Alldredge, E.E. Aladova, S.E. Glover and V.V. Vostrotin. Metabolism and Dosimetry of Actinide Elements in Occupationally-exposed Personnel of Russia and the United States: A Summary Progress Report. Health Phys. 79(1):63-71; 2000.

Love, C.L. Diseases and Primary Causes of Death Among 276 USTUR Registrants. Published in Proceedings of the Topical Meeting on Radiation Protection for our National Priorities; Medicine, the Environment and the Legacy. Spokane, WA, September 17-21, 2000. American Nuclear Society, La Grange Park, IL. Pp. 83-86; 2000.

Russell, J.J. A Survey of USTUR Actinide Contaminated Wound Cases. Published in Proceedings of the Topical Meeting on Radiation Protection for our National Priorities; Medicine, the Environment and the Legacy. Spokane, WA, September 17-21, 2000. American Nuclear Society, La Grange Park, IL. (Abstract) Pp. 83-86; 2000.

Russell, J.J. and R. L. Kathren. Uranium Deposition in a Whole Body Donation to the USTUR. (Abstract) Health Phys. 78(6):S129; 2000.

Suslova, K.G.. V.F. Khokhoryakov and R.E. Filipy. Effect of Health on Systemic Distribution and on Urinary Excretion of Plutonium in Workers Exposed by Inhalation at Radiochemical Plants. Published in Proceedings of the Topical Meeting on Radiation Protection for our National Priorities; Medicine, the Environ- ment and the Legacy. Spokane, WA, September 17-21, 2000. American Nuclear Society, La Grange Park, IL. Pp. 56-63; 2000.

Uehara, S., L.H. Toburen, W.E. Wilson, D.T. Goodhead and H. Nikjoo. Calculations of Electronic Stopping Cross Sections for Lowenergy Protons in Water. Radiation Phys. and Chemistry 59:1-11;2000.

\section{Submitted}

Brooks, A.L., S. Bao, K. Rithidech, L.A. Couch and L.A. Braby. Relative Effectiveness of $\mathrm{HZE}{ }^{56} \mathrm{Fe}$ Particles for the Induction of $\mathrm{Cy}$ togenetic Damage In Vivo. Rad. Research.

Elliston, J. T., S.E. Glover and R.H. Filby. The Determination of Natural Uranium in Human Tissues By Recovery Corrected Kinetic Phosphorescence Analysis. Journal of Radioanalytical and Nuclear Chemistry.

James, A.C., R.E. Filipy, J.J. Russell and J.F. McInroy. USTUR Case 0259 Whole Body Donation: A Comprehensive Test of the Current ICRP Models for the Behavior of Inhaled ${ }^{238} \mathrm{PuO}_{2}$ Ceramic Particles. Health Phys.

Khokhryakov, V.F., K.G. Suslova, V.V. Vostrotin, S.A. Romanov, Z.S. Memshikh, T.I. Kudravtseva, S.C. Miller, M.P. Krahenbuhl and R.E. Filipy. Lung Clearance of Occupational Plutonium Intake at Late Stages After Intake. Health Phys.

Russell, J.J., M.R. Sikov and R.L. Kathren. Plutonium Content of Human Placental Tissues. Health Phys.

Russell, J.J. Interstitial Lung Disease of Occupational Origin: A Case Report. Abstract submitted for oral presentation at the $46^{\text {th }}$ Annual Health Physics Society meeting in Cleveland, Ohio on June 10-14, 2001. 
Russell, J.J. and R.L. Kathren. Uranium Deposition and Retention in a USTUR Whole Body Case. Health Phys.

Sikov, M.R., and J.J. Russell. Fetoplacental Dosimetry of Plutonium Burdens Incurred Prior to Pregnancy. Abstract submitted for poster presentation at the $46^{\text {th }}$ Annual Health Physics Society meeting in Cleveland, Ohio on June 10-14, 2001.

Wilson, W.E., D.J. Lynch, K. Wei and L.A. Braby. Microdosimetry of a $25 \mathrm{KeV}$ Electron Microbeam. Rad. Research.

\section{In Preparation}

Elliston, J. T. and R.H. Filby. Comparing the Determination of Natural Uranium in Human Tissues by Traditional Kinetic Phosphorescence Analysis Versus Recovery Corrected Kinetic Phosphorescence Analysis.

Glover, S.E., J.T. Elliston, G. Deckert, D.B. Stuit, R.H. Filby and R.E. Filipy. Bone Calcium Content as a Predictor of the Contents of Actinide Elements in the Human Skeleton.

\section{Presented}

March 2000

Filipy, R.E. presented "Metabolism and Dosimetry of Plutonium Industrial Compounds" at the symposium Chronic Radiation Exposure: Possible Biological Indications symposium in Chelyabinsk, Russian Federation.

\section{April 2000}

Bao, S. presented a poster entitled "Induction of Cytogenetic Damage by HZE ${ }^{56} \mathrm{Fe}$ Particles in vivo in Dividing and Non-dividing Cells at the annual Radiation Research Society meeting in Albuquerque, NM.

Elliston. J T. presented "Comparing the Deter- mination of Natural Uranium in Human Tissues by Traditional Kinetic Phosphorescence Analysis Versus Recovery Corrected Kinetic Phosphorescence Analysis" at the 5th International Conference on Methods and Applications of Radioanalytical Chemistry, Marc V Conference in Kona, HI.

Filipy, R.E. presented a talk on the progress regarding Rocky Flats workers who were USTUR Registrants to the Former Radiation Worker Medical Surveillance Program Advisory Committee meeting in Denver, CO.

Filipy, R.E. gave a presentation on the USTUR to the Rocky Flats Occupational Medicine Group in Denver, CO.

June 2000

Russell, J.J. presented "Uranium Deposition and Retention in a Whole Body Donation to the USTUR" at the 45th annual Health Physics Society Meeting in Denver, CO.

Russell, J.J. presented an overview of the USTUR report covering the biology, pathology, actinide retention and excretion in 32 Registry wound cases to the NCRP Committee 5717 meeting on Radionuclide Dosimetry Model for Actinide Wounds in Denver, CO.

\section{September 2000}

Dagle, G.E. presented "High Exposure to Americium: A Review of the Hanford Accident Case" at the joint Health Physics-American Nuclear Society regional meeting held in Spokane, WA.

Filipy, R.E. presented "A Collaborative Research Project Involving the Human Tissue Analysis Programs of the United States and the Russian Federation" at the joint Health Physics-American Nuclear Society regional meeting held in Spokane, WA. 
Jacobson, B. presented "Cataracts in Retired Workers with Transuranic Exposure Histories" at the joint Health Physics-American Nuclear Society regional meeting held in Spokane, WA.
Love, C.L. presented "Diseases and Primary Causes of Death Among 276 USTUR Registrants" at the joint Health Physics-American Nuclear Society regional meeting held in Spokane, WA.

\section{ADVISORY COMMITTEE HIGHLIGTS}

\section{Advisory Committee Meeting}

Report of the Scientific Advisory Committee of the Department of Energy's U.S. Transuranium and Uranium Registries. Summary of results by members in attendance at the annual Advisory Committee meeting, held September 14-16, 2000, at the University Inn, Moscow, ID.

\section{Executive Summary}

The meeting included a visit by some of the Committee members to the USTUR-related laboratories at the Nuclear Radiation Center in Pullman.

The well-organized meeting allowed an exchange of ideas on the mission of the USTUR and on the approaches to meeting the goals of this mission. There was consensus that the USTUR is fulfilling an important function in providing valuable data on radiation safety. Discussions centered around: technical issues of obtaining and analyzing autopsy materials, presentation of data in formats that are useful for both scientists and for the general public, and focusing of efforts on Registrants who have been exposed to sufficient uranium or transuranium radionuclides to warrant complete analysis of autopsy materials.
Major recommendations include:

1. A long-term plan that includes clear and rational priority criteria must be developed to provide guidelines for accepting biological materials from Registrants and for processing these materials in the most meaningful and cost-effective manner;

2. Information in user-friendly formats must be provided to the Department of Energy and to the public in order to ensure continued support for USTUR operations;

3. Plans must be developed and implemented for upgrading the laboratory at Washington State University in order to ensure safety and efficiency of operation.

More specific recommendations are included in the body of the report.

\section{Introduction}

The current USTUR program began as the U.S. Plutonium Registry in 1968 at the Hanford Atomic Products Operation in Richland. Washington. It was later merged with the Uranium Registry and operated by the Hanford Environmental Health Foundation. Since 1992, the 
U.S. Transuranium and Uranium Registries (USTUR) have been maintained by Washington State University under a grant from the Department of Energy (DOE). As a university program the Registries have the advantages of being integrated into an academic setting, involving other university personnel, access to specialized analytical capabilities, and student participation in research activities.

In addition, the Registries are guided by an external Scientific Advisory Committee (SAC), which is comprised of seven individuals with expertise in health physics, radiochemistry, medicine, and labor relations. The SAC meets at least annually to review the progress and objectives of the Registries. This oversight by the SAC and the performance of research in an academic setting assures the quality and independence of the Registries' work.

The Advisory Committee meeting brought together:

1. Directorship for the U.S. Transuranium and Uranium Registries;

2. Program Manager from the U.S. Department of Energy Headquarters;

3. Faculty from Washington State University and active researchers from the Registries scientific staffs in Richland and Pullman; and

4. Four members of the Scientific Advisory Committee. One member was added to the committee this year, Kathryn P. George. Department of Philosophy at the University of Idaho, Moscow, ID.

The attitude throughout was cordial but business-like, and there was a clear, favorable attitude of the new administration under Director, Dr. Ronald Filipy. Part of the day preceding the main meeting was a walk-through of the radiochemistry laboratory and discussions with their staff.

\section{Members and Guests in Attendance}

Advisory Committee Members:

Aldrich, Joe

Oak Ridge Associated Universities

Rocky Flats Environmental Technical Site Golden CO

Brosemer, Ronald

School of Molecular Biosciences

Washington State University

Pullman, WA

Fisenne, Isabel

Environmental Measurements Laboratory

New York, NY

George, Kathryn

Department of Philosophy

College of Letters and Science

University of Idaho

Moscow, ID

Thomas, Robert G.

Committee Chairman

Consultant

Folsom, CA

Department of Energy Representative:

Brooks, Barbara

USTUR Program Manager

Office of Environment, Safety, and Health, DOE

Germantown, MD 
College of Pharmacy:

Fassett, William

Dean

College of Pharmacy

Quock, Ray

Department Chair

Pharmaceutical Sciences

Scoles, Diana

CFAO

College of Pharmacy

Brown, Twila

Principal Assistant

Pharmaceutical Sciences

USTUR Faculty and Staff:

Filipy, Ronald

Director

Russell, John

Associate Director

Ehrhart, Susan

Program Administrative Manager

Elliston, James

Director of Radiochemistry

Alldredge, J. Richard

Statistician

Love, Cheryl

Research Technologist

Pham. Minh

Systems Analyst

Stuit, Dorothy

Radiochemist

Deckert, Gail
Radiochemist

Invited Guests:

Suslova, Klara

Foreign Scientist

Aladova, Elena

Foreign Scientist

Sokolnikov, Mikhail

Foreign Scientist

\section{Comments from the Executive Session}

The executive meeting of the SAC was very lively this year (2000), with input from all attending committee members. Notes were jotted down onto a flip chart, and these notes were transmitted to the committee members by the chairman, following the meeting. The topics of interest, which are more fully discussed in other sections of this report, dealt with the following items:

1. Prefer next meeting to be in the Tri Cities in mid-September 2001, information on the agenda be sent in advance, and distribute copies of slides at the meeting-suggest using PowerPoint and use 6-slides per page format for hard copies;

2. Equipment upgrades and safety issues regarding the radiochemistry laboratory;

3. USTUR and operational health physicists should continue increased interaction:

4. Employ critical judgment on which USTUR data can be disseminated with confidentiality; consider issues involved and develop options which can be discussed with the Committee; 
5. Strategy for more discretion in acceptance of new applicants. Current criteria are:

- a form authorizing release of medical and health physics information;

- a questionnaire about exposure and work history, completed by applicant; -USTUR reviews the above forms, compares them with criteria for acceptance, and makes a determination;

-YES or NO decision;

- if YES, 1 of 2 autopsy consent forms are sent;

- the registrant must agree to have their own data, excluding personal identifiers, included in the database.

6. New strategy might include categorization of registrants by radionuclide level, (e.g. 1,2,3), there should be a column on the data sheets for this category, and letters regarding the categorization could be sent to the Registrant.

7. Tissue samples currently in-house that are not adequate to meet new, triage criteria should not be given analytical priority;

8. Copies of the consent forms should be distributed to committee members for review;

9. Payment for performing the autopsy is provided by contract; the last payment should be held up if samples are not received in acceptable form. or an enforceable action for not following autopsy procedures should be developed;

10. The Committee wants an explanation of the relevancy of work on thorotrast and Am241 to USTUR objectives;

11. Should the brain be included in the list of tissues routinely analyzed;

12. Need a more user-friendly inventory of the tissue holdings in NHRTR, what radionuclide(s), which freezer, etc.; and should be certain that USTUR samples get first priority for analysis;

13. Need ideas for USTUR performance measures, such as the number of queries per year, communications with the Registrants, tracking responses, evaluations of renewals of Registrants on a periodic time scale, tracking requests for applications, cost per sample from beginning to final analyses, conduct a customer survey, etc.

\section{Considerations for the Future}

Thinking ahead, the next 10 years will most likely represent the highest rate of incoming tissue samples containing measurable activities that the USTUR will probably ever see in the history of the program. The concern being raised here is, what preparations, if any, is the USTUR making to handle, store, inventory, process, analyze, and report on these tissues in a reasonable amount of time following receipt of the samples (say within $1-3$ years after receipt of samples).

As a recommendation, a plan needs to be developed now to address the following issues:

1. What quantities of samples are anticipated each year over the next 10 years based on the age of the participants?

2. What are the potential shortcomings that affect the processing throughput (fume hoods, muffle furnaces, cold storage, wet chemistry, etc.)?

3. Action plans should be developed that identify these shortcomings and how they 
will be addressed in a reasonable timeframe. Plans should include keeping the SAC members informed of ongoing and future preparations for handling the potential increase in incoming tissue samples over the next few years.

An important immediate effort of the USTUR is to provide the DOE program manager, Barbara Brooks, with specific information to educate the new, incoming DOE administrators on the contribution and value of the Registries to DOE. Also, the new legislation to compensate former DOE and contractor workers for alleged harmful exposures to toxins and radionuclides will highlight the relevance of the information generated by the USTUR. Some of the information that could be useful to DOE include metrics such as the cost per full-time employee, the cost per analysis, tracking requests to become a Registrant and linking them to events or sites and whether related to former or current workers, evaluating renewal of applicants on an annual basis and conducting a survey through the Health Physics Society as to the value of the USTUR to the worker community, as well as the professional and scientific communities. Other metrics would be the number of hits on the USTUR web site and tracking the number of phone and E-mail inquiries as to subject, etc. This information support is crucial as the budgetary support for February 1,2001 to 2002 is soft and funding beyond that is unknown.

The USTUR was conceived as a source of information and tools for operational health physicists. The information generated by the Registries should be compared with models mandated for use within DOE facilities.

Although obvious personal identifiers are removed. how to preserve confidentiality when disseminating USTUR data is a matter of concern. The USTUR staff was tasked to con- sider the issues involved and to develop options which can be discussed with the full committee. The framework would encompass the policies of WSU and DOE in dealing with such information. Our newest member, Kathryn Paxton George, should be especially helpful to the staff as a sounding board.

The committee advised the USTUR that Thorotrast cases should be given a very low priority as these were medical exposures, not occupational uranium or transuranic exposures.

\section{Operational Criteria for Potential Future Registrants}

A "triage" scheme needs to be set-up which will have critical elements for the acceptance of new registrants. Current Registrant cases should be evaluated in light of the likelihood that substantive information of value to the health physics and scientific communities will result from the eventual analyses. Some factors could be the nuclide, the form of the nuclide, the type of exposure, availability and quality of urinalysis or other bioassay results, etc. In this regard, the policies and procedures of the USTUR must be followed strictly with the realization that selectivity is necessary for both fiscal and scientific reasons. USTUR staff will propose a strategy for categorization of Registrants that reflects priority for analysis. One suggestion was to graphically (or in tabular form) present the human "clinical effects" data as a function of the whole body dose from a radionuclide, using both the USTUR and the Russian experiences. If the potential Registrant has a body burden which clearly indicates a level at which no biomedical effect has been seen in the past, then the limited value in accepting this person versus cost and effort needs to be transmitted to the potential Registrant or his/her spouse. There must be some control in place before the potential workload exceeds possibility. 
It is inappropriate to accept potential candidates into the program where there is no actinide analysis data for USTUR staff to review. Having access to viable actinide data would enable staff to defend their decision for either accepting or not accepting a potential candidate. Therefore, decisions that are based on working level month (WLM) data do not represent a satisfactory analysis data set. WLM's are based on non-actinide airborne exposure to radionuclides such as radon and radium.

The question of the eligibility of former uranium miners or archived tissue from such workers to become part of the population served by USTUR was resolved by pointing out the charter of the Registries. There must be a record of at least one bioassay sample (urine analysis) which indicated an internal, occupational exposure to uranium. Exposure to radon and its progeny does not qualify a person as a potential participant in the USTUR.

There was considerable discussion of honoraria to families and payments for autopsies. Although it was suggested that the honorarium be dropped entirely, the Committee recommends that the family honorarium be continued but not increased.

The matter of inadequate performance of autopsies by contractors was discussed. The USTUR has managerial control of the contract established with anyone collecting the requested tissues. There definitely should be a clause in the contract stating that if the tissue collection is not performed to the satisfaction of the USTUR, the USTUR has the right to withhold some portion of the full payment based on poor performance of the subcontractor.

\section{Comments on Radiochemistry Operations}

On Thursday, September 14, 2000 an onsite tour was held at WSU's Nuclear Radiation
Center, which houses the Registries' radiochemical laboratories. The general perception of this tour follows:

1. The laboratories were neat and clean. They were well organized given the allocated space and available equipment. It was noted that their current procedures manual is $90 \%$ complete, and it should be fully updated as soon as possible. The logbooks were in order as were the chain-of-custody records of samples received and processed. All records and logbooks that were reviewed were current and up-to-date. Each of the pieces of equipment had current calibration stickers properly posted. The laboratory staff was well prepared to respond to a wide range of questions. Their demeanor was that of self-assured confidence. They were very approachable when being queried on both general and specific topics. Furthermore, they exhibited a sense of pride for their work and were willing to share both their successes and their failures. Each of them exhibited a broad base of knowledge that ranged from environmental issues, waste disposal, equipment calibration requirements, safety systems, operational procedures, chain-of-custody, sample preparation and analysis, and specifics related to the counting systems.

2. Some laboratory features need attention now and others need to be addressed in the near future. It should be expected that there will be an increasing quantity of tissues becoming available each year over the next eight years. Initially, this impacts the limited storage capacity, followed then by fume hood availability, wet chemistry facilities, muffle furnace capacities, etc. For the second year, the safety issue of a faulty fume hood in the analytical laboratory was discussed. A more 
immediate safety concern is the safety of anyone working in Room 114. The existing exhaust plenum is currently leaking acid onto the head of anyone walking under the ductwork which is centered over the middle of the aisleway on the south side of the center table. If the acid doesn't hit a person it hits the floor, which results in a slick spot on the floor that contributes to the potential of lost workdays from slips/ trips/and falls. The worker's safety cannot be properly addressed by covering the pinhole leaks with green duct tape. A further concern with this exhaust duct is that the penetration through the roof allows leakage of environmental contaminates into Room 114. A second concern is that one of the available fume hoods has been out of service for over nine months waiting to be painted with corrosive resistant paint.

3. Another fume hood has been occupied with research activities which limited its availability for routine operations. For improved throughput, there is currently a definite lack of available fume hood space. The issue of the capital equipment money is subservient to the DOE Environmental, Safety and Health issue. The staff should assemble a package of exactly what hardware, installation, related ductwork, etc. is needed, and the cost of each component. This will also give them insight into means of obtaining the necessary funds, perhaps from WSU.

4. The analysts need to review and revamp their bone ashing protocol. The use of borosilicate glass vessels has at least two disadvantages: oven temperature must be limited to prevent melting of the vessel and the vessels are fragile. If there is a reason for not using either metal or silica trays, other than use of glass vessels the way it has been done in the past, it should be written into the ashing procedure in the analytical methods manual. If use of borosilicate glass continues, then again, the procedures should be modified. The suggestion is that after two days at $500{ }^{\circ} \mathrm{C}$, the oven will be cooled down and sample(s) removed. The bone should be cracked open and broken into small pieces. Contamination can be avoided by the use of a Diamondite mortar and pestle. Diamonite is finely powdered synthetic sapphire with a hardness similar to tungsten carbide. The carbon remaining in the bone sample will be more available for oxidation in the dry ashing process. While it appears that there is no problem in keeping a bone sample in an oven for up to 40 days, it is a highly unusual procedure and does not follow from "no problem". The other approach is to dry ash a bone for a few days, dissolve it in acid and filter off any carbonaceous and/or siliceous material. The filter should then be analyzed for the nuclide(s) of interest to show that no activity is associated with the undissolved material. This should be done on several samples and sample types to document the findings. The elimination of excessive dry ashing times and subsequent (probably) unnecessary use of Teflon beakers, HF, etc. will more than pay for the analytical work required for the procedural changes.

\section{Miscellaneous Operational Remarks}

The whole body case in which the internal exposure has been attributed solely to U-234 should be revisited. Some of the archived tissues from this case should be measured by a completely independent technique. In addition, the records associated with the occupational settings of this participant should be carefully reviewed. Some additional follow-up may be required to clarify the circumstances of such 
an extraordinary exposure to U-234.

It is not clear whether analyses for Am-241 are being performed only on cases with known exposures to Am or are Am-241 analyses performed on persons with Pu exposure as an indication of Pu-241 concentration during exposure.

There are virtually no human data available on uranium in brain tissue. This is an issue not only because of the Oak Ridge worker epidemiological study, but it is also an emerging issue with the veterans wounded with depleted uranium. The USTUR has an opportunity to fill a need for DOE, DOD, toxicologists and metabolic modelers.

The USTUR, through WSU, has several adjunct professors as volunteer staff. The Committee wants to know who they are, what projects are they working on, what has been their progress and applicable time-lines for the completion of their work. The Committee suggested that with limited resources and, even with unpaid adjuncts, the data developed from the human cases must have higher priority than the beagle dog data.

The establishment of a database with a complete inventory of USTUR information and tissues is still a work in progress. The database format has not been decided but the thinking is toward the CEDR format. The database would include such information as the nuclide of interest, how the tissue was preserved, the location of the tissue and much more. Once the USTUR database is complete and functional, the NHRTR would require attention so it can be linked to it.
Dr. Filipy's discussion of last year's recommendations was gratifying and encouraging to the Committee. Good progress has been made on most of them. A conference call with the Committee members and USTUR administrative staff is planned for early February 2001. 


\section{APPENDIX A \\ ABSTRACTS OF PUBLISHED PAPERS}

USTUR-0130-98

Calculations of Electronic Stopping Cross Sections for Low-energy Protons in Water Uehara, S. ', L.H. Toburen', W.E. Wilson', D.T. Goodhead and H. Nikjood. Radiation Phys. and Chemistry 59:1-11; 2000.

Calculations of electronic stopping cross sections for low-energy protons were performed using available interaction crosssections and information on the mean energy loss per collision. The results were compared with published stopping power data to assess the general consistency and reliability of the results. The calculated stopping cross sections include contributions from excitation by both the proton and neutral-hydrogen components of the charge-equilibrated beam and the mean energy lost per interaction. The calculated electronic stopping cross section for swift charge-equilibrated hydrogen particles in water are in agreement with previous tabulations of stopping power to within $20 \%$ (approx.) for particles energies less than 0.3 $\mathrm{MeV}$.

aSchool of Health Sciences, Kyushu University, Maidashi 3-3-1, Higashi-ku, Fukuoka 812-8582, Japan; 'Department of Physics, East Carolina University, Greenville. NC 27858, USA; 'U.S. Transuranim and Uranium Registries, Washington State University, Tri-Cities, Richland, WA 99352. USA; "Medical Research Council (MRC) Radiation and Genome Stability Unit. Harwell. Osfordshire OX11 ORD. UK.

\section{USTUR-0131-98}

Scientific and Administrative History of the United States Transuranium and Uranium Registries. Kathren, R.L. * Technology 7(24): $165-180: 2000$.

This paper documents the administrative and scientific history of the United States Transuranium and Uranium Registries, since their inception as the National Plutonium Registry in 1968. The Registries are a unique postmortem human tissue research program studying the biokinetics, dosimetry and possible biological effects in persons with known intakes of plutonium, uranium and the other actinide elements. The scientific evolution of the program over its three-decade history is traced through brief discussion of some of the more significant scientific findings of the Registries, including contributions to biokinetic modeling, and bioeffects.

*College of Pharmacy, Washington State University-Tri-Cities, 2710 University Dr., Richland, WA 99352.

\section{USTUR-0143-99}

Metabolism and Dosimetry of Actinide Elements in Occupationally-Exposed Personnel of Russia and The United States: A Summary Progress Report. Khokhrvakov. V.F. ${ }^{*}, K . G$.

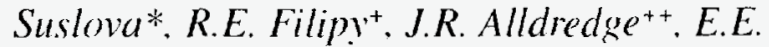
Aladova*. S.E. Glover and V. V. Vostrotin* Health Phys. 79(1):63-71: 2000. 
The United States Transuranium and Uranium Registries (USTUR) and the Dosimetry Registry of the Mayak Industrial Association (DRMIA) have been independently collecting tissues at autopsy of plutonium workers in their respective countries for nearly $30 \mathrm{y}$. The tissues are analyzed radiochemically and the analytical data are used to develop, modify, or refine biokinetic models that describe the depositions and translocation of plutonium and transplutonium elements in the human body. The purpose of this collaborative research project is to combine the unique information on human, gathered by the two Registries, into a joint database and perform analyses of the data. A series of project tasks are directly concerned with dosimetry in Mayak workers and involve biokinetic modeling for actinide elements. Transportability coefficients derived from in-vitro solubility measurements of actinide-containing aerosols (as measured by the DRMIA) were related to specific workplaces within Mayak facilities. The transportability coefficients of inhaled aerosols significantly affected the translocation rates of plutonium from the respiratory tract to the systemic circulation. Parameters for a simplified lung model, used by Branch No. 1, Federal Research Center Institute of Biophysics (FIB-1) and the Mayak production Association for dose assessment at long times after inhalation of plutoniumcontaining aerosols, were developed on the basis of joint USTUR and DRMIA data. This model has separate sets of deposition and transfer parameters for three aerosol transportability groups, allowing work histories of the workers to be considered in the dose-assessment process. FIB-1 biokinetic models were extended to include the distributions of actinide elements in systemic organs of workers, and a relationship between the health of individual workers and plutonium distribution in tissues was determined. Workers who suffered from liver diseases generally had a smaller fraction of systemic plutonium in the liver at death and a larger fraction in the skeleton than did relatively healthy workers. Also, the fraction of total systemic plutonium excreted per day was significantly greater for workers with liver diseases than for relatively healthy workers. These observations could have a considerable effect on organ dosimetry in health-impaired workers whose dose assessments were based solely on urinary excretion rates. A comparison of this model to other biokinetic models, such as those published by the International Commission for Radiological Protection, is currently underway as is the documentation of uncertainty estimates associated with the model.

${ }^{*}$ Branch No. 1, Federal Research Center Institute of Biophysics, Ozersk Rd. 19, Ozersk, Chelyabinsk Region, Russia, 456780; ${ }^{+}$The United States Transuranium and Uranium Registries, Washington State University - Tri-Cities, 2710 University Dr., Richland, WA 99352; ${ }^{++}$Program in Statistics, Washington State University, Pullman, WA 99164-3144; ${ }^{\#}$ The United States Transuranium and Uranium Registries, Washington State University, Pullman, WA 99164-1302.

\section{USTUR-0149-99}

Combination of the Actinide Analysis Data of Two Human Tissue Analysis Programs: Triumphs and Problems. Filipy, R.E.*, J.R. Alldredge*, S.E. Glover*, V.F. Khokhryakov', K.G. Suslova ${ }^{+}$, E.E. Aladova ${ }^{+}$and V.V. Vostrotin ${ }^{+}$. Published in Proceedings of the 2 nd International Symposium on Chronic Radiation Exposure: Possibilities of Biological Indication. Chelyabinsk, Russian Federation, March 14-16, 2000. Urals Research Center for Radiation Medicine, Chelyabinsk, Russian Federation. (Abstract) Pp. 87-88; 2000.

The United States Transuranium and Uranium Registries (USTUR) and the Dosimetry Reg- 
istry of the Mayak Industrial Association (DRMIA) are the two primary human tissue analytical programs known to the world. Each Registry has collected actinide element exposure information and analytical data from tissues collected at autopsy of occupationally exposed workers in plutonium and uranium processing facilities. The two Registries have been collaborating to combine their data into a joint database for use in the study of uptake, retention, translocation, and excretion of actinide elements in humans. During the four-year collaborative research project, a number of similarities and differences in the methods used to collect the data were found. This report contains a discussion of the similarities and some of the major differences.

The methods for analyzing tissue samples used by the two Registries were quite different in the past; however, a series of sample exchanges with comparisons of the analytical results has shown the results to be in close agreement. One parameter used by both Registries that was not in agreement was the "residence time", the time between exposure, or probable exposure, of a worker to the actinides and the death of the individual. Another difference between the Registries involved the methods used in calculation of skeletal actinide content on the basis of a limited number of bone samples collected at autopsy. An explanation of these differences with an evaluation of their impacts, along with potential solutions will be presented. These differences, discovered during the collaborative project, did not preclude the use of the data, either separately or combined, to characterize the biokinetics of actinide elements in the human body.

*U.S. Transuranium and Uranium Registries, Washington State University, Washington, USA: 'Branch No. 1, Federal Research Center-Institute of Biophysics, Ozyorsk, Russian Federation.

\section{USTUR-0150-00}

Uranium Deposition and Retention in a USTUR Whole Body Case. Russell, J.J.' and R.L. Kathren (Abstract) Health Phys. 78(6):S129; 2000.

This report describes a whole body donation from a person with a documented occupational intake of uranium. USTUR Case 1002 was an adult male who died from an acute cerebellar infarct at the age of 83. He worked as a power operator, utility operator, and metal operator for 28 years in a facility that processed and handled radioactive materials. Although he suffered a number of burns from hot metal and acids, cuts, abrasions, and puncture wounds during his many years of work, there were no corresponding health physics or medical records to indicate that these occurrences needed or required excision or decontamination due to the suspicion of the deposition of radioactive material. Over the course of his employment, USTUR Case 1002 submitted numerous urine samples for $\mathrm{U}, \mathrm{Pu}$ and fission product analysis. The highest single $U$ value measured during this time period was $\sim 30$ ugL- 1 recorded in during the second year of his employment. A urinary bioassay sample taken before termination of employment measured $4.3 \mathrm{up} / \mathrm{L}$. The mean urinary $U$ concentration per liter per year calculated from the employee's bioassay records covering the first eleven years of monitoring averaged less that $3 \mathrm{ug} / \mathrm{L}$. The ratio of $234 / 238 \mathrm{U}$ activity in the lung tissue was about 1 , same as that found in natural uranium. The highest concentration of $U$ was found in a tracheobronchial lymph node. Because this was a highly insoluble uranium material, the $U$ content in the various tissues of the body followed a rank order lung $>$ skeleton $>$ liver $>$ kidney. The concentration of the $U$ in the kidney tissue was $1.98 \mathrm{ng} / \mathrm{g}$ which is about 3 orders of magnitude less than the generally accepted threshold level for permanent kidney damage of $3 \mathrm{ug}$ 
$\mathrm{U} / \mathrm{g}$ and roughly equal to the $1.4 \mathrm{ng} / \mathrm{g}$ reported for Reference Man. The results of the autopsy disclosed findings not uncommon in the aged: severe atherosclerosis, areas of sclerotic kidney glomeruli, with stromal fibrous scaring and moderate to severe arterionephrosclerosis. Lung sections contained parenchymal areas of acute vascular congestion and a mil degree of anthracosis.

'U.S. Transuranium and Uranium Registries, College of Pharmacy, Washington State University 2710 University Dr., Richland, WA. 99352; 'College of Pharmacy, Washington State University, 2710 University Dr., Richland, WA 99352.

\section{USTUR-0158-00}

The United States Transuranium and Uranium Registries: What the Human Data Have Shown. Kathren, R.L. ', and J.J. Russell'. Published in Proceedings of the Topical Meeting on Radiation Protection for our National Priorities; Medicine, the Environment and the Legacy. Spokane, WA, September 17-21, 2000. American Nuclear Society, La Grange Park, IL. Pp. $75-82 ; 2000$.

Postmortem studies of tissues obtained at autopsy from volunteer donors with known intakes of transuranics have shown that contrary to the commonly accepted models based primarily on animal studies, plutonium and americium have different biokinetics and an appreciable deposition in the soft tissues of the body as well as the established skeleton and liver depots. While the ICRP model and biokinetic parameters for plutonium are reasonably consistent with the human tissue observation, the clearance half time of americium in the liver was found to be only about 2.5 years, considerably shorter than put forth by the ICRP. Plutonium was shown to concentrate in human placenta, possibly indicative of the placenta serving as a biological filter. Measurement of plutonium, americium and uranium in the lungs and associated lymph nodes of occupationally exposed person revealed clear differences between smokers and nonsmokers, indicative impaired clearance and a higher lung dose in smokers. Studies of tissues obtained at autopsy from a person with massive accidental intake of americium were consistent with observations of biokinetics in other cases with smaller intakes. A small but clear diminution of all blood cell lines was observed soon after intake, possibly with some subsequent recovery, and with further diminution towards the end of life. The hematological effect and changes in bone remodeling including bone hyperplasia are likely attributable to the massive dose of $360 \mathrm{~Sv}$ to the bone and $10,400 \mathrm{~Sv}$ to the bone surfaces. There was no evidence of radiation-associated malignancy and although the individual suffered cataract, the dose to the eyes was below the catarogenic dose. A study of the causes of death among the first 260 donors to the USTUR revealed no excess causes of death attributable to radiation exposure. An excess number of brain tumor deaths were observed, but these all occurred at a single work site and are thought to be attributable to other causes. Studies of whole body Thorotrast donors to the USTUR indicate that commonly accepted risk coefficients for alpha induction of bone sarcoma might be too high while those for leukemia are a factor of six too low. Future Cytogenetic studies utilizing these unique materials and techniques such as fluorescent in situ hybridization hold promise of determining with a high degree of confidence the presence or absence of low-level radiation effects as well as identifying specific genetic factors involved in radiation carcinogenesis.

${ }^{1}$ College of Pharmacy, Washington State University-Tri Cities, 2710 University Dr., Richland, WA 99352. 'U.S. Transuranium and 
Uranium Registries, College of Pharmacy, Washington State University, 2710 University Dr., Richland, WA 99352.

\section{USTUR-0159-00}

Induction and Repair of HZE Induced Cytogenetic Damage. Brooks, A.L. ${ }^{1}$, K. Rithedech ${ }^{2}$, W.B. Chrisler, L.A. Couch ${ }^{1}$ and L.A. Braby ${ }^{3}$. Published in Proceedings of the 1st International Workshop on Space Radiation Research and 11 th Annual NASA Space Radiation Health Investigators' Workshop. Arona, Italy, May 2731, 2000. NASA, Washington, DC. (Abstract) Pp. 35-36; 2000.

Risk from prolonged manned space flight includes the radiation exposure from Galactic Cosmic rays containing high energy, heavy ions like ${ }^{56} \mathrm{Fe}$. Studies were conducted at the Brookhaven National Laboratory by exposing Wistar rats to high mass and energy (HZE) particles using the Alternating Gradient Synchrotron (AGS). The animals were sacrificed, and the frequency of micronuclei induced in the respiratory tract cells was defined as a function of time after radiation in vivo. The biological effectiveness of ${ }^{56} \mathrm{Fe}$ ions (1000 GeV/AMU) relative to low-LET gamma rays and high-LET alpha particles for the induction of micronuclei was also determined. In animals sacrificed within one day of radiation exposure, the frequency of micronuclei in rat lung fibroblasts, epithelial cells and tracheal epithelial cells increased linearly with slopes of 7 X 10-4, $1.2 \mathrm{X}$ 10-3 and 1.1 X 10-3 micronuclei/binucleated cell/Gy, respectively. After 49 days or recovery or repair in vivo the frequency of micronuclei in the tracheal epithelium till showed a significant increase as a function of exposure but the slope was only $1 / 10$ that observed when the animal were sacrificed on the day of exposure. For the deep lung fibroblasts and deep lung epithelial cells, there was no dose related increase in the frequency of micronuclei. This suggested that there was in vivo loss or repair of the cells containing the radiation induced Cytogenetic damage. It was determined in respiratory tract cells that the HZE exposure was between 0.9 and 3.3 times as effective in producing micronuclei as ${ }^{60} \mathrm{Co}$. However, the HZE exposures were only 0.2 times as effective as radon in producing micronuclei in either deep lung or tracheal epithelial cells. Studies are being conducted to determine the fraction that induced by delta rays. These calculations suggest that much of the energy deposited by the primary HZE particles is "wasted" for the production of micronuclei relative to the energy deposited by radon or other ionizing radiation.

${ }^{1}$ Washington State University-Tri-Cities, Richland, WA. ${ }^{2}$ New York University at Stony Brook, Stony Brook, NY.; ${ }^{3}$ Texas A\&M University, College Station, TX.

\section{USTUR-0161-00}

A Collaborative Research Project Involving the Human Tissue Analysis Programs of the United States and the Russian Federation. Filipy, R.E.*, V.F. Khokhryakov ${ }^{+}$, K.G. Suslova ${ }^{+}$and E.E. Aladova ${ }^{+}$. Published in Proceedings of the Topical Meeting on Radiation Protection for our National Priorities; Medicine, the Environment and the Legacy. Spokane, WA, September 17-21, 2000. American Nuclear Society, La Grange Park, IL. Pp. 3-9; 2000.

The United States Transuranium and Uranium Registries (USTUR) is a human tissue analysis program established for the purpose of characterizing the distribution of actinide elements in the human body. The U. S. Department of Energy, Office of Epidemiology and Health Surveillance, provides the support for the program and it is operated by the Washington State University, College of Pharmacy. 
Tissues are collected at autopsy of volunteer donors who worked at facilities that processed uranium, plutonium, or other transuranic elements. The tissues are analyzed by the USTUR radiochemistry laboratory and the results of the analyses are contained in an automated database along with information about exposure histories and the medical histories of the donors. Such data are useful for comparing estimates of actinide intakes, made during life, with the body burdens measured after death and for the deposition and translocation of the actinides among body organs.

The USTUR and the Dosimetry Registry of the Mayak Industrial Association (DRMIA) have been engaged in a collaborative research project for the past five years. Both Registries collect tissues from workers at plutonium processing facilities and analyze those tissues for plutonium content. The purpose of this collaborative research project was to combine the data collected by both Registries for the purpose of characterizing the biokinetics of plutonium in the human body.

Analyses of these data were directed toward characterization of a plutonium biokinetics model used by the DRMIA for internal dose assessments at the Mayak facility. Relationships between model parameters and the workplace aerosols inhaled by workers at Mayak were demonstrated as was a relationship between the health status of an individual and plutonium excretion rates.

*The U.S. Transuranium and Uranium Registries, Washington State University-Tri-Cities, Richland, WA 99352; ${ }^{+}$Branch No. 1 of the Federal Research Center Institute of Biophysics Ozersk, Russian Federation.

\section{USTUR-0162-00}

Effect of Health on Systemic Distribution and on Urinary Excretion of Plutonium in Workers Exposed by Inhalation at Radiochemical Plants. Suslova, K.G.*, V.F. Khokhryakov* and R.E. Filipy ${ }^{+}$. Published in Proceedings of the Topical Meeting on Radiation Protection for our National Priorities; Medicine, the Environment and the Legacy. Spokane, WA, September 17-21, 2000. American Nuclear Society, La Grange Park, IL. Pp. 56-63; 2000.

This paper presents the results of a joint Russia-USA investigation of the health impairment effects on distribution of plutonium between the liver and the skeleton and on the urinary excretion rate in workers at the Mayak radiochemical plant (Russia) and USA nuclear industry facilities. The results were obtained by radiochemical analysis of soft tissues and bone samples collected at autopsy of about 400 workers who died suddenly from acute coronary diseases and accidents (relatively healthy workers) and those who died from serious diseases (mainly tumors) of the organs. In Mayak cases the healthy individuals had mean skeleton-to-liver contents of $50 \%$ and $38 \%$, respectively, of systemic plutonium. With the formation of pathological processes in the body, the fraction deposited in the liver decreased and a large portion of the systemic fraction that left the liver entered the skeleton. In individuals with serious diseases of the liver (cirrhoses and carcinoma of the liver), the relative content in the liver decreased by $25 \%$; almost all the plutonium that was redistributed appeared to go to the skeleton, where the relative content increased by $24 \%$. The mean systemic fractions in the skeleton and the liver were $74 \%$ and $13 \%$, respectively. Systemic plutonium fractions in organs were statistically significantly different between the two groups. In USTUR cases, the systemic plutonium fractions in the liver were higher than in the skeleton for all health 
groups. In a person of normal health, the relative content in the liver averaged $50 \%$ and the relative content in the skeleton was $37 \%$. But with pathological processes in the body, the systemic plutonium fraction in the liver decreases appreciably and the fraction was $31 \%$ for individuals who died with a marked liver impairment. The plutonium fraction in the skeleton increased from $37 \%$ to $56 \%$ with health impairment. In addition to a redistribution of plutonium from the liver to the skeleton, marked liver impairment also results in an increased rate of urinary excretion. In relatively healthy individuals, the urinary excretion factor (daily plutonium excretion divided by systemic plutonium content) was $\mathrm{K}_{\mathrm{e}}=1.54 \times 10^{-5}$ day 1 . There was a statistically significant increase in the value of $\mathrm{K}_{\mathrm{e}}$ in persons with serious diseases. The data indicate that using the urinary excretion factor, $\mathrm{K}_{\mathrm{e}}$ without consideration of the health state of an individual can lead to serious overestimation of plutonium body burden and to dose and risk estimates based on the bioassay data.

*Branch No. 1 SRC RF-Institute of Biophysics, Ozyorskoe shosse 19, Ozyorsk, Russia 456780; ' U.S. Transuranium and Uranium Registries, Washington State University, Richland, WA 99352.

\section{USTUR-0164-00}

Cataracts in Retired Heavy-Nuclide-Exposed Radiation Workers. Jacobson, B.S ${ }^{1}$. Published in Proceedings of the Topical Meeting on Radiation Protection for our National Priorities; Medicine, the Environment and the Legacy. Spokane, WA, September 17-21, 2000. American Nuclear Society, La Grange Park, IL. (Abstract) Pp. 53; 2000.

Increased incidence of cataracts has been observed in radiotherapy patients and in people exposed to nuclear radiation at Hiroshima, Nagasaki and Chernobyl. Age-related eye cataracts are predominantly of the nuclear and the cortical type, while radiation-induced and injury-induced cataracts are predominantly of the posterior subcapsular (PSC) type. Generally accepted ocular radiation protection standards are based on the assumption that radiation cataracts are deterministic and appear only when a relatively high dose threshold, about $2 \mathrm{~Gy}$, is exceeded. Hall et al., (1999) and Wilde and Sjostrand (1977) found increased risk of cataracts in adults whose eyes had been irradiated in childhood with doses of $0.5 \mathrm{~Gy}$ or less. These exposures were incidental consequences of X-ray therapy for hemangiomas. A number of studies suggest a stochastic basis for radiation cataract (Brown, 1997, Vano et al., 1998). This would imply that the radiation safety standards set for workers and for the general population might be inadequate. Therefore it is important for the risk assessment community to know whether cataract formation is indeed a stochastic response to radiation.

Medical records of 76 living USTUR Registrants from the Hanford site were searched for information regarding cataracts. Physicians of 57 Registrants were queried. Few primary care physicians had useful records of lens status; however local ophthalmologists were able to supply relevant data. Of 44 Registrants for whom ophthalmologic information was obtained, 28 or 64 percent had cataracts. Of these, 3 were of the unknown type. Recorded radiation exposures of the three PSC cases were less than $1 \mathrm{mSv}$. However, the validity of neutron and Transuranic dosimetry records from the early days of the nuclear program is not beyond question.

${ }^{1}$ U.S. Transuranium and Uranium Registries, Washington State University, Richland, WA 99352. 


\section{USTUR-0165-00}

Diseases and Primary Causes of Death Among 276 United States Transuranium and Uranium Registrants. Love, C.L'. Published in Proceedings of the Topical Meeting on Radiation Protection for our National Priorities; Medicine, the Environment and the Legacy. Spokane, WA. September 17-21, 2000. American Nuclear Society, La Grange Park, IL. Pp. 83-86; 2000.

This is a report of the known diseases and primary causes of death among 276 United States Transuranium and Uranium Registrants (USTUR). The causes of death and gross anatomical diagnosis obtained from the autopsy reports and death certificates are classified according to the International Classification of Diseases, $9^{\text {th }}$ Revision, Clinical Modification (ICD-9-CM) in the USTUR Clinical Database. This information, in conjunction with medical history, dosimetry data and radiochemical analysis of collected tissues, will contribute significantly in understanding the health effects of actinides in humans. With a few exceptions, USTUR Registrants are diagnosed with the same kinds of diseases that affect the United States population.

'U.S. Transuranium and Uranium Registries, Washington State University, Richland, WA 99352.

\section{USTUR-0167-00}

A Survey of USTUR Actinide Contaminated Wound Cases. Russell. J.J. Published in Proceedings of the Topical Meeting on Radiation Protection for our National Priorities; Medicine, the Environment and the Legacy: Spokane. WA, September 17-21, 2000. American Nuclear Society; La Grange Park, IL. (Abstract) Pp. 55: 2000.
Since 1978, the United States Transuranium and Uranium Registries (USTUR) have been studying the biokinetic distribution, and possible deleterious effects associated with human intakes of the actinide elements, including uranium. By far, the largest number of USTUR Registrants have incurred their actinide body burdens via inhalation, followed by mixed intakes from wounds alone. The routes of accidental intake were taken from the Registrants health physics records supplied by their former employers. In those cases where no recorded incident report existed and the employee had a positive bioassay and or a measurable body burden, it was assumed that the intake took place at very low levels over many years and was thus classified as chronic inhalation. To date, 32 cases have been identified as wound and/or inhalation incidents, and 12 identified as wounds only. Several of these wound cases were treated via chelation therapy and or surgical excision of the wound site. In addition to the actinide cases, the USTUR has also collected autopsy tissue samples and radiochemical data from two whole body donors who had received intravenous injections of Thorotrast, a colloidal suspension of thorium dioxide. The similarities between the sub dermal and intramuscular depositions of Thorotrast with the resultant tissue/cellular responses to those of DUinduced wounds in former military service personnel are somewhat comparable. In this study, we examine not only the translocation of alpha activity from the wound site but also the histological, physiological and molecular events that are set in motion following the accidental intake or induced wounds from the internal deposition of alpha emitters. Some or all these same induced changes or events are probable precursors leading to the inductions of fibrosis seen in various tissues following long term alpha particle irradiation (i.e. thorotrastomas, and pniumosclerosis and bone marrow fibrosis) seen in some Pu workers 